\title{
EFEITO DA FRAGMENTAÇÃO FLORESTAL NA PREDAÇÃO DE SEMENTES DA PALMEIRA JERIVÁ (Syagrus romanzoffiana) EM FLORESTAS SEMIDECÍDUAS DO ESTADO DE SÃO PAULO
}

\author{
MARINA FLEURY
}

Dissertação apresentada à Escola Superior de Agricultura "Luiz de Queiroz”, Universidade de São Paulo, para a obtenção do título de Mestre em Ecologia de Agroecossistemas.

\author{
PIRACICABA \\ Estado de São Paulo - Brasil \\ Julho - 2003
}




\title{
EFEITO DA FRAGMENTAÇÃO FLORESTAL NA PREDAÇÃO DE SEMENTES DA PALMEIRA JERIVÁ (Syagrus romanzoffiana) EM FLORESTAS SEMIDECÍDUAS DO ESTADO DE SÃO PAULO
}

\author{
MARINA FLEURY
}

Bióloga

Orientador: Prof. Dr. MAURO GALETTI RODRIGUES

Dissertação apresentada à Escola

Superior de Agricultura "Luiz de

Queiroz”, Universidade de São Paulo, para a obtenção do título de Mestre em Ecologia de Agroecossistemas.

\author{
PIRACICABA \\ Estado de São Paulo - Brasil \\ Julho - 2003
}




\section{Dados Internacionais de Catalogação na Publicação (CIP)} DIVISÃO DE BIBLIOTECA E DOCUMENTAÇÃO - ESALQ/USP

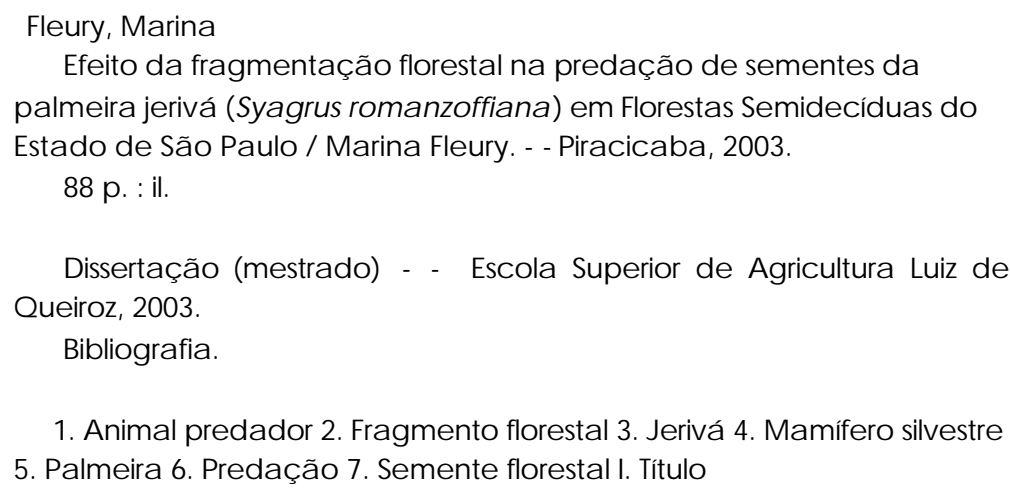

1. Animal predador 2. Fragmento florestal 3. J erivá 4. Mamífero silvestre 5. Pa Imeira 6. Predação 7. Semente florestal I. Título

CDD 634.6

\section{"Permitida a cópia total ou parcial deste documento, desde que citada a fonte - $\mathrm{O}$ autor"}


De dico

ao me u afilhado,

o sapinko go õo, aos seus pais, avós e bisos. 


\section{AGRADECIMENTOS}

Aos professores Mauro Galetti, Pedro Jordano, Thadeu Couto, Luciano Verdade e Carlos Alberto Vetorazzi e seus alunos pela ajuda prestada. Agradeço aos colegas do LEA, pelos cafezinhos durante as tardes e churrascos as sextas.

À Capes, Fapesp (96/10464-7) e Junta de Castilla y León pelo financiamento.

Ao Sr. Magalhães (Faz. Barreiro Rico), à Fazenda São José, ao Condomínio Colinas do Atibaia e ao Instituto Florestal por me autorizarem a trabalhar em seus fragmentos. À Célia, funcionária do IF na Estação Ecológica dos Caetetus, por ser sempre tão atenciosa conosco.

À Laís, Flávia: Maria Flávia, Vinícius, Priscilla, Adriana, Christine, Mica, Janda, Bóris, Mussum, Pisgüi e Mink, grandes companheiros piracicabanos. À Marisa e "nuestros heroes".

Ao Diego, por ser meu grande companheiro e por me ajudar com o trabalho de campo. Para finalizar, àminha famíli a (incluindo a Huete Verdugo) e amigos. 


\section{SUMÁRIO}

Página

LISTA DE FIGURAS. .......................................................................................... vii

LISTA DE TABELAS ......................................................................................... ix

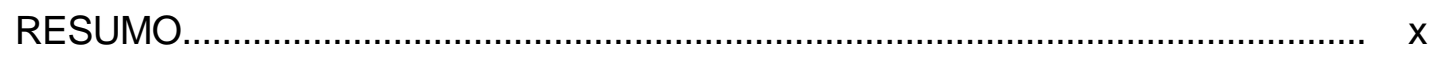

SUMMARY

1 INTRODUÇÃO

2 REVISÃO DE LITERATURA............................................................................... 5

2.1 A fragmentação florestal.................................................................................... 5

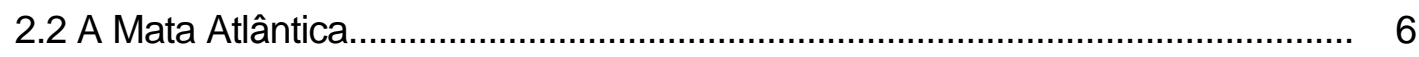

2.2.1 As palmeiras da Mata Atlântica.......................................................................... 8

2.2.1.1 Consequêencias da defaunação e da fragmentação nas populações de palmeiras .......................................................................................... 9

2.2.2 Efeitos causados pela fragmentação florestal.............................................. 11

2.2.2.1 Efeito de borda

2.2.2.2 Extinção em fragmentos florestais.......................................................... 12

3 MATERIAL E MÉTODOS............................................................................ 14

3.1 Descrição da espécie............................................................................... 14

3.2 Áreas de estudo................................................................................... 15

3.2.1 Parque Estadual do Morro do Diabo (MD)............................................. 15

3.2.2 Estação Ecológica dos Caetetus (EEC) ..................................................... 17 
3.2.3 Fazenda Barreiro Rico - Vivaeiro-Tabatingüera (VT) e Monal (Mo)............ 20

3.2.4 Mata da Fazenda São José (SJ).......................................................... 22

3.2.5 Mata do Ribeirão Cachoeira (RC) ....................................................... 24

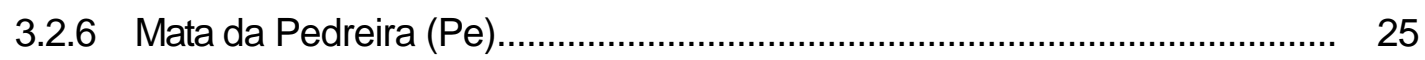

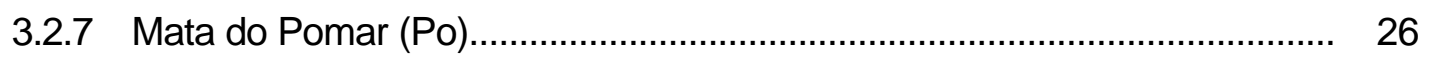

3.3 Predação de sementes de Syagrus romanzoffiana................................... 28

3.4 Caracterização da estrutura dos microhábitats......................................... 31

3.5 Análise estatística.............................................................................. 35

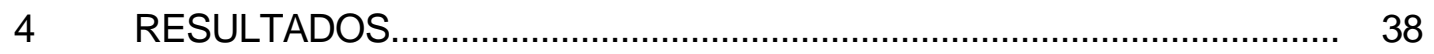

4.1 Predação de sementes de S. romanzoffiana............................................... 38

4.2 Características da estrutura dos microhábitats.......................................... 43

5 DISCUSSÃO

5.1 Predação de sementes de Syagrus romanzoffiana.................................... 49

5.2 Características da estrutura dos microhábitats.............................................. 53

5.3 A fragmentação florestal e a predação de sementes de Syagrus romanzoffiana........................................................................................... 57

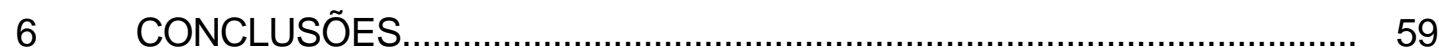

REFERÊNCIAS BIBLIOGRÁFICAS ............................................................. 61 


\section{LISTA DE FIGURAS}

Página

1 Diagrama da metodologia utilizada para o estabelecimento dos pontos amostrais nos oito fragmentos de Floresta Semidecídua no Estado de São Paulo

2 Metodologia empregada para o levantamento das características estruturais de vegetação dos microhábitats de borda, interior de mata e clareira, aplicado em cada estação experimental dos oito fragmentos avaliados (MD, EEC, VT, Mo, SJ, RC, Pe e Po).

3 Percentagem total de sementes de Syagrus romanzoffiana predadas (preto), e percentagem relativa nos três microhábitats a mostrados, borda $(\mathrm{BO}$, cinza escuro), clareira (CL,cinza) e interior de mata (IM, branco) nos oito fragmentos de Floresta Semidecídua amostrados.

4 Semente de Syagrus romanzoffiana predada por cateto (Pecari tajacu) e/ou queixada (Tayassu pecari).

5 Semente de Syagrus romanzoffiana predada por pequeno roedor.

6 Sementes de Syagrus romanzoffiana predada por esquilo (Sciurus ingrami)......

7 Diagrama de Shepard para a validação do modelo de Escalonamento Multidimensional não métrico, gerado com as variáveis estruturais dos microhábitats de borda, interior de mata e clareira nos oito fragmentos de Floresta Semidecídua testados 
8 Dispersão dos valores dos autovetores gerados pela análise de escalonamento multidimensional não métrico (MDS) com as variáveis estruturais dos microhábitats de borda $(=\mathrm{BO})$, interior de mata $(\bullet=\mathrm{IM})$ e clareira $(\boldsymbol{\square}=\mathrm{CL})$ nos oito fragmentos de Floresta Semidecídua (Po, Pe, RC, SJ, Mo, VT, EEC e MD). As formas elipsóides são os agrupamentos de (A) clareira, (B) borda e $(C)$ interior de mata.................................................................................... 


\section{LISTA DE TABELAS}

Página

1 Lista de mamíferos não voadores do Parque Estadual do Morro do Diabo (Cüllen, 1997)

2 Lista de mamíferos não-voadores da Estação Ecológica dos Caetetus (Cüllen, 1997). 18

3 Lista de mamíferos não voadores da mata do Vivaeiro Tabatingüera (1.471 ha), fragmento florestal pertencentes àFazenda Barreiro Rico.

4 Lista de mamíferos não voadores da mata do Monal ( $374 \mathrm{ha}$ ), fragmento florestal pertencentes àFazenda Barreiro Rico

5 Lista de mamíferos não voadores da Mata da Fazenda São José (SJ).

6 Lista de mamíferos não-voadores encontrados no fragmento florestal Mata do Ribeirão Cachoeira (Gaspar, 1997; dados não publicados).

7 Lista de mamíferos não-voadores do campus "Luiz de Queiroz", da Universidade de São Paulo (Gheler-Costa, 2002).

8 Classes dos intervalos de distância do ponto amostral à estrutura mais próxima

9 Índice de forma (SI) dos fragmentos MD (Parque Estadual do Morro do Diabo), EEC (Estação Ecológica dos Caetetus), VT (Mata do Vivaeiro Tabatingüera), Mo (Mata do Monal), SJ (Mata São José), RC (Mata do Ribeirão Cacheira), Pe (Mata da Pedreira) e Po (Mata do Pomar). 


\title{
EFEITO DA FRAGMENTAÇÃO FLORESTAL NA PREDAÇÃO DE SEMENTES DA PALMEIRA JERIVÁ (Syagrus romanzoffiana) EM FLORESTAS SEMIDECÍDUAS DO ESTADO DE SÃO PAULO
}

\author{
Autora: MARINA FLEURY \\ Orientador: Prof. Dr. MAURO GALETTI RODRIGUES
}

\section{RESUMO}

O processo de fragmentação florestal, além do isolamento e da redução de hábitat, produz um aumento do microhábitat de borda. Este aumento leva à gradual perda de diversidade devido a alterações abióticas e bióticas fazendo com que remanescentes florestais não comportem a mesma diversidade que hábitats contínuos. $O$ estabelecimento de espécies vegetal depende crucialmente do local onde as sementes são depositadas no ambiente, porém muito pouco se sabe sobre os efeitos da fragmentação florestal para a manutenção das características abióticas e bióticas dos microhábitats e seus efeitos na sobrevivência de sementes pós-dispersas, uma vez que a maioria dos estudos foi conduzida em florestas contínua. Este estudo teve como objetivo avaliar os efeitos da fragmentação florestal na predação de sementes da palmeira Syagrus romanzoffiana ("jerivá") em três microhábitats (clareira, borda e interior de mata), testando oito fragmentos de Floresta Semidecídua (de 9,5 a $33.845 \mathrm{ha}$ ). Os objetivos deste trabalho foram os de avaliar (1) se existe diferenças bióticas e abióticas entre os microhábitats de borda, interior de mata e clareira; (2) se o tamanho do fragmento florestal exerce influência para a 
manutenção das características do microhábitats amostrados; (3) se os microhábitats testados diferem na sobrevivência de sementes de $S$. romanzoffiana pós-dispersas; (4) se o tamanho do fragmento influencia na taxa de predação de sementes; (5) quais das características estruturais avaliadas estão relacionadas com a predação de sementes de $S$. romanzoffiana e (6) quais as características estruturais que estão correlacionadas com o amanho do fragmento. Foi concluído que fragmentos menores que 20 ha não possuem diferenças abióticas e bióticas por extrapolação da borda da mata a todo o fragmento, não sendo registrada nenhuma semente predada nestas áreas. Fragmentos de 230 a 380 ha possuem alta taxa de predação de sementes, sendo encontradas em todo o remanescente independente do microhábitat à medida que os fragmentos florestais com área superior a 1000 ha possuem uma menor taxa de predação e distinções abióticas e bióticas entre clareira, interior e borda de mata. Para a conservação de populações de jerivá em fragmentos florestais com área inferior a 1.000 ha são necessários planos de manejo, como medidas que visem o desenvolvimento de sub-bosque em fragmentos que estejam inteiramente sob efeito de borda, e a proteção de sementes pós-dispersas em fragmentos onde haja forte pressão de predadores de sementes. Investigações sobre os efeitos das alterações decorrentes do processo de fragmentação florestal na biologia reprodutiva de angiospermas são de suma importância para planos efetivos de planejamento, conservação e restauração, gerenciamento de áreas florestais. 


\title{
THE EFFECT OF FOREST FRAGMENTATION ON Syagrus romanzoffiana (PALMAE) SEED PREDATION IN SEMI-DECIDUOUS FOREST
}

\author{
Author: MARINA FLEURY \\ Adviser: Prof. Dr. MAURO GALETTI RODRIGUES
}

\section{SUMMARY}

The effects of forest fragmentation, more than isolation and habitat reduction, increase the microhabitat edge. This increasing leads to gradual biodiversity loss because of abiotic and bioic alterations, doing that forest fragments support less species when compared with continuous forest. The establishment of plants depends crucially on the place where their seeds were deposited on the environment, but very little is known about the effects of forest fragmentation on microhabitats abiotic and biotic conditions maintenance and their effects for seed survival, once that most studies have been carried out in large forest. In this study, we evaluate the effects of forest fragmentation on Syagrus romanzoffiana seed predation in three microhabitats (gaps, understory and forest edge), testing eight semi-deciduous forest fragments (9.5 to 33,845 ha). Our objectives were to test (1) if there are abiotic and biotic differences among gap, understory and forest edge; (2) if the size of forest fragment influence the maintenance of microhabitats condition; (3) if the microhabitats differs on S. romanzoffiana seed survival; (4) if forest size influence on seed predation rate; (5) which structure characteristics evaluated are related with $S$. romanzoffiana seed predation; and (6) which structure characteristics are 
related with forest fragment area. We conclude that forest with less than 20 ha do not support abiotic and biotic distinction, with the forest edge overspread the whole reminiscent. In these forest fragments, we did not find any seed predated. Fragments with 230 to 380 ha had higher seed predation rates, with no differences among the tested microhabitats. Forest fragments with more than 1,000 ha differ among microhabitats biotic ally and idiotically, and had lower seed predation. We conclude that for Syagrus romanzoffiana populations be conserved in isolated forest areas with less than 1,000 ha are necessaries managing plans, as developing understory at remnants with the whole area under edge effect, and post-dispersed seed protection at fragments with high seed predation. The knowledge of the effects of forest fragmentation on angiosperms reproductive processes is essentially for managing, planning, restoration and conservation of forested areas. 


\section{INTRODUÇÃO}

As florestas tropicais, definidas por Norman Myers (1984) como "a melhor celebração da vida na Terra", têm sido foco de pesquisas com caráter conservacionista devido ao fato de não existir outro ecossistema que se iguale em diversidade de espécies e na complexidade ecológica (Laurance \& Bierregaard, 1997 e Withmore, 1997). Os ecossistemas tropicais retêm metade do número de espécies mundiais em somente $7 \%$ da área do planeta e, apesar de sua importância biológica, as matas vêm sendo amplamente desmatadas, fragmentadas, queimadas, suas madeiras exploradas e seus animais caçados em taxas alarmantes (Wilson, 2001).

A fragmentação e perda de hábitat são processos intimamente relacionados (Laurance \& Bierregaard, 1997). A alteração da cobertura do solo produz, além da perda direta de hábitat, a redução no tamanho das populações e aumento na distância entre fragmentos, efeito que dificulta intercâmbio de indivíduos ou a reposição por recolonização de eventuais extinções. Um dos efeitos mais evidentes oriundos do processo de fragmentação florestal é o aumento da relação perímetro/superfície das florestas, aumentando da permeabilidade as condições impostas pelo ecossistema periférico por efeito de borda (Estrada \& Coates-Estrada, 2002; Hill \& Curran, 2001; Honnay et al., 2002 e Turner, 1996).

A borda da mata pode ser considerada um microhábitat transicional entre os ecossistemas florestal e o adjacente, cuja criação pode induzir a alterações microclimáticas (Báldi, 1999; Camargo \& Kapos, 1995; Copplestone et al., 2000; Jose et al., 1996; Kapos, 1989; Kapos et al., 1997; Malcolm, 1994; 
Matlack, 1994; Turton \& Freidburger, 1997; Willians-Linera, 1990 e Young \& Mitchell, 1994), causando aumentos na mortalidade de árvores (Laurance et al.,1998; 2000; e Williamson et al., 2000), na densidade arbórea (WilliamsLinera, 1990), no desenvolvimento vegetal e na invasão de espécies arbóreas (Brothers \& Spingarn, 1992 e Murcia, 1995), e diminuição do recrutamento de plântulas (Benítez-Malvido, 1998 e Wahungu et al., 2002).

Estas alterações resultam na formação de um microhábitat antrópico, distinto dos florestais, com diferente composição de espécies e estrutura da vegetação (Brown \& Hutchings, 1997; Laurance, 1991; 1994; Lovejoy et al., 1986 Restrepo et al., 1999; Restrepo \& Gómez, 1999 e Saunders et al., 1991). Em longo prazo estas alterações podem afetar drasticamente os processos ecológicos como polinização, predação, comportamento territorial e hábitos alimentares das espécies (Janzen, 1988; Laurance, 1991; 1994; Lovejoy et al., 1986; Restrepo \& Gomez, 1999 e Restrepo et al., 1999) levando à perda da diversidade de plantas e animais, e em casos extremos, ocasionando total defaunação (Brown \& Heske, 1990; Redford, 1992 e Terborgh, 1988).

O tamanho do fragmento influencia fortemente nos processos ecológicos, principalmente devido as mudanças induzidas pela formação da borda (Collinge, 1996). A intensidade do efeito de borda é inversamente proporcional ao tamanho do fragmento (Ranta et al., 1998). Conseqüentemente, fragmentos pequenos possuem maior proporção de ambiente alterado, e assim, espécies vegetais e animais que dependem das condições exclusivas do interior da mata perdem seus hábitats pela expansão da borda ao interior do remanescente (Stevens \& Husband, 1998).

Pequenos fragmentos florestais podem não possuir condições típicas de interior de mata, e como resultado podem sofrer mudanças dramáticas na composição natural de espécies de mamíferos (Fonseca \& Robinson, 1990; Laurance, 1994; Stevens \& Husband, 1998 e Yahner, 1988).

Os microhábitats possuem condições bióticas e abióticas próprias, as quais diferem em qualidade para a sobrevivência de sementes e plântulas 
(Benítez-Malvido \& García-Gúzman, 1999; Burkey, 1993; Cintra, 1997 a; b; Laurance, 1994; Malcolm, 1994; Russell \& Schupp, 1998; Schupp \& Frost, 1989; Schupp \& Fuentes, 1995; Schupp, 1988 a; b; e 1993). Laurance (1994) e Malcolm (1994) sugerem que a predação de sementes na borda da mata possa ser alta devido à grande densidade de pequenos mamíferos neste microhábitat; porém Burkey (1993) constatou que há uma diminuição na predação de sementes por roedores àmedida que se aproxima da borda da mata .

Nos fragmentos florestais existe uma maior incidência de clareiras formadas por quedas de árvores devido ao aumento da ação dos ventos (Laurance, 1994; Laurance et al., 1998; 2000 e Malcolm, 1994). Estudos indicam que em clareiras há um aumento de patógenos e, conseqüentemente, maior taxa de mortalidade de sementes (Auspurger, 1983 e 1984), além de pequenos e médios mamíferos predadores de sementes (como pacas e ratos) usarem este microhábitat como abrigo contra seus predadores naturais (Emmons, 1982 e Schupp, 1988 c). Autores testando a predação de sementes em clareiras e interior de mata encontraram maiores taxas de predação nas clareiras, concluindo que este microhábitat não corresponde a um local seguro ("safe site") para o estabelecimento de sementes (Augspurger, 1983; 1984; Cintra, 1997 e Schupp et al., 1989).

A maioria dos estudos realizados com predação de sementes não considera o tamanho da área estudada e/ou o possível efeito da defaunação nesse processo (Burkey, 1993; Cintra, 1997 a; b; Forget \& Milleron, 1991; Forget, 1997; Janzen \& Martin, 1982; Russell \& Schupp, 1998; SánchezCordero \& Martínez-Gallardo, 1998; Schupp, 1988 a; b; 1990; Schupp \& Frost, 1989; Schupp \& Fuentes, 1995; Smythe, 1986 e 1989; porém veja Santos et al.1999; Santos \& Tellería, 1994; Tellería et al., 1991; Wright et al., 2000 e Wright \& Duber, 2001).

Os objetivos deste trabalho foram avaliar (1) se existe diferenças bióticas e abióticas entre os microhábitats de borda, interior de mata e clareira; (2) se o tamanho do fragmento florestal exerce influência para a manutenção 
das características do microhábitats amostrados; (3) se os microhábitats testados diferem na sobrevivência de sementes de Syagrus romanzoffiana pósdispersas; (4) se o tamanho do fragmento influencia na taxa de predação de sementes; (5) quais das características estruturais avaliadas estão relacionadas com a predação de sementes de $S$. romanzoffiana e (6) quais as características estruturais que estão correlacionadas com o tamanho do fragmento.

Investigações como esta são importantes para a conservação de florestas tropicais, uma vez que as reservas atuais se encontram em sua maioria na forma de pequenos fragmentos defaunados sob alta influência dos efeitos de borda (Laurance, 1999). A compreensão dos processos ecológicos "chave" podem trazer informações fundamentais para o manejo de espécies florestais e recuperação de áreas degradadas. Em florestas tropicais os processos de reprodução e de sobrevivência vegetal, para a maioria das espécies, envolvem interações com animais (Silva \& Tabarelli, 2000). A manutenção das áreas manejadas ou recuperadas dependerá da presença dos processos de interação animal-planta, como polinização, frugivoria, dispersão e predação de sementes e herbivoria. 


\section{REVISÃO DE LITERATURA}

\subsection{A fragmentação florestal}

A fragmentação florestal é o processo no qual áreas contínuas são subdivididas em áreas de tamanho reduzido devido a destruição do hábitat (Lovejoy et al., 1986), constituindo ilhas do ecossistema original inseridos em uma matriz com diferentes ecossistemas (Saunders et al., 1991). Porém nem sempre fragmentos podem ser inferidos como ilhas pois, dependendo da permeabilidade da matriz e do grau de isolamento, o remanescente pode ter um alto fluxo de animais e propágulos (Metzger, 2000 e Steffan-Dewender et al., 2002).

Grande parte dos sistemas fragmentados não sustenta a mesma diversidade de espécies encontradas em ecossistemas originais por influência do "efeito de borda" (Burkey, 1993; Carvalho \& Vasconcelos, 1999; Chiarello, 1999; Lovejoy et al., 1986; Lynam \& Billick, 1999; Mesquita et al., 1999; Sizer \& Tanner, 1999 e Tabarelli et al., 1999). A transição entre o fragmento florestal e o ecossistema adjacente é muito abrupta, criando uma borda que expõe a floresta às condições encontradas na matriz adjacente. A porção externa da mata adjacente à borda se torna parte da zona de transição, ocasionando mudanças microclimáticas, como aumento da temperatura e ressecamento próximo a borda (Báldi, 1999; Jose et al., 1996; Turton \& Freidburger, 1997; Willians-Linera, 1990, Young \& Mitchell, 1994) acarretando em alterações na composição de espécies e na estrutura da vegetação (Brand \& George, 2000; King \& DeGraaf, 2002; Laurance, 1991; 1994; Lovejoy et al., 1986 Moruzzi et 
al., 2002 e Saunders et al., 1991). Em longo prazo a alteração da estrutura florestal pode afetar drasticamente os processos ecológicos como polinização, predação, comportamento territorial e hábitos alimentares das espécies (Aizen \& Feinsinger 1994 a; b; Cadenasso \& Pickett, 2000l; Janzen, 1988; Laurance, 1991; 1994; Lovejoy et al., 1986; Myster \& Pickett, 1993; ), causando perda da diversidade de plantas e animais, e em casos extremos, levando a total defaunação (Brown \& Heske, 1990; Redford, 1992 e Terborgh, 1988).

\subsection{A Mata Atlântica}

Atualmente, não só a comunidade científica mas diversos setores como a mídia e a população em geral, têm observado atentamente o processo de fragmentação e destruição de florestas tropicais. Este interesse se dá por ser um fenômeno mundial e por sua importância na conservação da biodiversidade (Conservation-International, 2000; Myers et al., 2000 e Viana \& Tabanez, 1997). A Mata Atlântica possui altos níveis de diversidade biológica e endemismo (Conservation-International, 2000), contendo 7\% das espécies mundiais, muitas endêmicas no status de ameaçadas de extinção (Quintela, 1990), o que associado ao fato de ser um dos ecossistemas mais ameaçados do mundo, faz com que esse bioma seja considerado um dos cinco mais importantes pontos quentes ("hotspots") para a conservação da biodiversidade do planeta (Myers et al., 2000).

Antes da chegada dos primeiros colonizadores europeus na costa brasileira durante o século XVI, a Mata Atlântica cobria de 1,0 a 1,5 milhões de quilômetros quadrados, estendendo-se do Rio Grande do Norte $\left(6^{\circ} \mathrm{N}\right)$ ao Rio Grande do Sul $\left(30^{\circ} \mathrm{S}\right)$, sendo a floresta tropical com maior gradiente latitudinal (Brown \& Brown, 1992 e SOS Mata Atlântica \& INPE, 1992) e representando $12 \%$ do total de cobertura do território brasileiro. Após quinhentos anos de colonização a Mata Atlântica é considerada um dos ecossistemas mais 
ameaçados do planeta (Brown \& Brown, 1992 e SOS Mata Atlântica \& INPE, 1992), com $95 \%$ das florestas devastadas e os $5 \%$ restantes encontradas como pequenos fragmentos florestais isolados e de difícil acesso (SOS Mata Atlântica \& INPE, 1992 e 1993).

A Mata Atlântica pode ser subdividida em duas regiões por diferenças pluviométricas e climáticas (Joly et al., 1991 e Leitão Filho, 1993). A primeira é constituída pela Floresta Ombrófila, a qual originalmente cobria toda a extensão da costa atlântica brasileira, e a segunda pela Floresta Semidecídua, situada a oeste estendendo-se àregião de planalto. A Floresta Semidecídua possui uma precipitação média anual inferior a da Floresta Ombrófila, com uma pronunciada estação seca durante o outono e o inverno (período entre os meses de abril a setembro).

Grande parte dos remanescentes de Mata Atlântica se encontra ao longo da costa (Floresta Ombrófila), ao passo que, devido às expansões industriais, urbanas e agrícolas, restam somente 280.000 ha de Floresta Semidecídua (SOS Mata Atlântica \& INPE, 1993), correspondendo a $2 \%$ da sua cobertura vegetal original e constituindo-se no ecossistema mais fragmentado e ameaçado do Domínio de Mata Atlântica (Viana \& Tabanez, 1996).

Originalmente as Florestas Semidecíduas cobriam a maior parte dos Estados de Minas Gerais, Rio de Janeiro, Paraná e São Paulo (Passos, 1998), e atualmente são fragmentos moldados pelo isolamento, extrativismo seletivo e incêndios, além dos reflexos das atividades agrícola, industrial e urbana (Viana \& Tabanez, 1996), porém ainda sustentam grande diversidade vegetal (Quintela, 1990 e Pagano, 1987). 


\subsubsection{As palmeiras da Mata Atlântica}

$\mathrm{Na}$ Mata Atlântica ocorrem 40 espécies de palmeiras, sendo muitas dessas endêmicas (Henderson et al., 1995). Estudos que descrevem dietas de aves e mamíferos neste bioma têm demonstrado que os frutos de palmeiras são utilizados por uma ampla variedade de animais, como psitacídeos, tucanos, morcegos, roedores e primatas Bonadie \& Bacon, 2000, Galetti et al., 1992; Galetti et al., 1999; Facure \& Giaretta, 1996; Facure \& Monteiro-Filho, 1996; Janzen, 1982; Olmos, 1997 e Reis et al., 2000).

Apesar da sua diversidade e importância para a fauna, estudos sobre as palmeiras da Mata Atlântica são escassos, com exceção de espécies com importância econômica, como o palmito juçara (Euterpe edulis; Cardoso et al., 2000; de Carvalho et al., 1999; Galetti et al., 1999; Matos \& Watkinson, 1998; Matos et al., 1999 e Reis et al., 2000).

Algumas populações de Euterpe edulis estão altamente ameaçadas pelo corte ilegal e exploração intensiva (Galetti \& Fernandez, 1998 e Reis et al., 2000). Os frutos do palmito são consumidos por pelo menos 30 espécies de aves e 15 de mamíferos (Galetti et al., 1999 e Zimmermann, 1999), sendo considerada "espécie chave" para diversas aves da Mata Atlântica (Sick, 1997). O corte massivo sem manejo do palmito certamente modifica drasticamente a comunidade de aves frugívoras, sendo que algumas podem depender dessa palmeira (Galetti \& Aleixo, 1998).

Assim como o palmito juçara, outras espécies de palmeiras da Mata Atlântica, como o jerivá (Syagrus romanzoffiana) podem estar sendo drasticamente afetadas por ações antrópicas - como pela perda de hábitats específicos para o seu estabelecimento ou pela extinção local de seus principais dispersores de sementes causados por perda de hábitat e/ou pressão de caça (Wright et al., 2000 e Wright \& Duber, 2001). A compreensão dos 
processos de interação ecológica animal-planta, bem como o estudo das causas das intervenções antrópicas nestes processos é um passo inicial e de fundamental importância para a conservação desta família.

\subsubsection{Conseqüências da defaunação e da fragmentação nas populações de palmeiras}

As palmeiras são reconhecidas como espécies importantes por exercerem um papel fundamental na alimentação de diversos animais nas florestas tropicais Zona \& Henderson, 1989). Esta característica, associada ao fato de muitas espécies de palmeiras serem assincrônicas fenologicamente, isto é, com período de frutificação distinto de outras espécies que tem frutos consumidos por animais e/ou possuírem longos períodos de frutificação, faz com que seus frutos sejam um recurso disponível em épocas de escassez de frutos e assim, alguns autores consideraram as palmeiras como "espécieschave" nesses ambientes (Peres, 1994 e Terborgh, 1986 a), apesar de poucos estudos terem testado essa hipótese (Galetti \& Aleixo, 1998).

Tanto a fragmentação florestal como a defaunação afetam diretamente a herbivoria e o recrutamento de diversas espécies tropicais (Terborgh et al., 1993; Wright et al., 2000 e Wright \& Duber, 2001). Poucos estudos, no entanto, êm investigado os efeitos desses processos sobre palmeiras e suas interações (Scariot, 1998; Wright et al., 2000 e Wright \& Duber, 2001).

Turner et al. (1996), compilando os resultados de estudos realizados em hábitats fragmentados, demonstrou que na maioria dos casos, fragmentos pequenos e isolados possuem menor riqueza de mamíferos, aves, anuros e insetos. Como os frugívoros têm sido indicados como o grupo dominante nas florestas tropicais (Terborgh, 1986 b), esses resultados sugerem que 
dispersores potenciais vêm sendo perdidos em diversos hábitats pelo processo de fragmentação.

Mamíferos de médio e grande porte (como cutias, porcos do mato e antas) são fundamentais na manutenção de diversos processos ecológicos, como a herbivoria, dispersão e predação de sementes, principalmente para plantas de sementes grandes como Syagrus romanzoffiana e outras espécies de palmeiras (Asquith et al., 1999; Dirzo \& Miranda, 1990; Forget, 1996 e Terborgh \& Wright, 1994). Além da sua vulnerabilidade à fragmentação por possuírem baixas densidades populacionais, esses animais são os mais procurados por caçadores (Peres, 2000 e Redford, 1992), de forma que muitos locais da Mata Atlântica já estão defaunados, e outros notadamente "florestas vazias" (sensu Redford, 1992).

Scariot (1999), avaliando os efeitos da fragmentação da Floresta Amazônica sobre a diversidade de palmeiras, forneceu indícios da vulnerabilidade dessas plantas à fragmentação ao demonstrar que fragmentos pequenos possuem uma menor riqueza de espécies no estágio de plântulas do que fragmentos maiores ou áreas contínuas. Por sua vez, Wright et al. (2000) estudando o efeito da caça na abundância de mamíferos e na dispersão e predação de duas espécies de palmeiras no Panamá demonstraram que tanto as abundâncias de mamíferos quanto a proporção de sementes dispersas são inversamente correlacionadas com a intensidade de caça. As evidências fornecidas por esses autores demonstram a necessidade de mais estudos avaliando o impacto da fragmentação e da defaunação sobre populações de palmeiras. 


\subsubsection{Efeitos causados pela fragmentação florestal}

\subsubsection{Efeito de borda}

O aumento da relação perímetro/superfície causados pelo processo de fragmentação florestal incrementa sua permeabilidade às condições ambientais e penetração de espécies exóticas encontradas nos hábitats periféricos (Estrada \& Coates-Estrada, 2002; Hill \& Curran, 2001 e Turner, 1996). Janzen (1986) indica a existência de ameaças externas, que afetam tanto as interações ecológicas como a persistência das espécies dentro dos fragmentos, de que se deriva o conceito de "efeito de borda". O efeito de borda é definido por Murcia (1995) como "uma zona ecótone, resultado da interação de ecossistemas, o florestal e o adjacente, separados por uma transição abrupta".

Em florestas contínuas o microhábitat de borda $₫$ restringe à área no entorno das clareiras formadas por deslizamentos ou queda de grandes árvores, nas margens de rios ou outros distúrbios naturais, mas em fragmentos florestais, torna-se um ambiente mais representativo. A redução em área decorrente do processo de fragmentação produz 0 aumento da relação perímetro/superfície (Ranta et al., 1998) e, conseqüentemente, fragmentos com pequenas áreas têm uma maior permeabilidade æ̀ condições ambientais encontradas nos hábitats periféricos decorrente da expansão da borda para 0 interior da mata (Fonseca \& Robinson, 1990; Chen et al., 1993 a; b; Laurance, 1994; Stevens \& Husband, 1998 e Yahner, 1988).

Existem três tipos de efeitos causados por ação da borda: os abióticos, os bióticos diretos e os bióticos indiretos. Os efeitos abióticos envolvem alterações nas condições microclimáticas, os bióticos diretos são as mudanças na composição, distribuição e abundância das espécies devido as alterações físicas próxima àborda, e os efeitos bióticos indiretos, que são as mudanças nas interações ecológicas como parasitismo, competição, predação, polinização e dispersão de sementes, decorrentes das mudanças causadas pelos efeitos 
bióticos diretos (Aizen \& Feinsinger, 1994 a; b; Doak et al., 1992; Laurance et al., 1997 e Murcia, 1995).

\subsubsection{Extinção em fragmentos florestais}

A transformação dos ecossistemas originais em cultivos e pastagens, e conseqüente expansão de bairros residenciais e/ou industriais próximos àárea agrícola são processos comumente observados (Withmore, 1997) e que causam perda de diversidade por efeitos da fragmentação, isolamento e redução superficial dos remanescentes florestais (Saunders et al., 1991).

A fragmentação florestal e a perda de hábitat são processos intimamente relacionados (Laurance \& Bierregaard, 1997). Os efeitos causados pelo Homem durante e após a atividade humana, porém, vão muito além da perda direta de hábitat, causando a redução do tamanho das populações e aumento na distância entre os remanescentes florestais, fatores que dificultam o intercâmbio de indivíduos e/ou reposição por recolonização a eventuais extinções. O aumento na relação perímetro/superfície nos fragmentos florestais aumenta sua permeabilidade não só às condições ambientais presentes nos ecossistemas adjacentes, mas também à penetração de espécies exóticas (Estrada \& Coates-Estrada, 2002; Hill \& Curran, 2001 e Turner, 1996), podendo representar uma ameaça æ̀s espécies locais.

Heywood et al. (1994) documentou que em ecossistemas tropicais o número de espécies extintas é muito inferior do que as esperadas pelas curvas de espécie-área. Na Mata Atlântica, apesar de ter sido reduzida a $5 \%$ de sua cobertura original, Brown \& Brown (1992) não registraram extinções de plantas vasculares, mamíferos, aves ou borboletas. Os autores inferem que a Mata Atlântica pode ter sempre existido como um grande mosaico de diferentes hábitats, cada qual composto por sua biota característica. 
As baixas taxas de extinção pode ser resultado do processo descrito por Channel \& Lomolino (2000), onde estudando a contração de hábitat de 245 espécies de diferentes grupos taxonômicos e regiões geográficas, concluíram que $90 \%$ das espécies estudadas persistem pelo menos na região periférica da área de vida, e sugerem que a porção externa seja considerada para a conservação de espécies. Brooks (2000), replicando Channel e Lomolino (2000), afirma que dados como os apresentados pelos autores são escassos para áreas consideradas "pontos quentes", e que áreas geograficamente marginais tendem a ser também ecologicamente marginais, sujeitas àextinção.

Corlett \& Turner (1997) e Turner et al. (1996) registraram a extinção de algumas espécies vegetais em Singapura, com a permanência de 99,8\% de espécies na floresta contínua contra $71 \%$ em fragmentos florestais. Os autores afirmam que há a possibilidade de que os indivíduos amostrados possam ter sido recrutados antes da extinção, uma vez que muitas espécies tropicais arbóreas são centenárias. Este fator pode estar relacionado com a baixa taxa de extinção de espécies arbóreas nos biomas tropicais. Corlett \& Turner (1997) notaram também que cerca de $50 \%$ das espécies de aves de interior de mata haviam sido localmente extintas, e que as espécies remanescentes eram de hábitos generalistas e que se tornaram abundantes.

Para Whitmore (1997), a hipótese de que a sobrevivência de espécies em fragmentos florestais é muito superior que a esperada na curva de espécie/área pode estar equivocada por não considerar que o fenômeno possa ser temporal. Muitas espécies não possuem número suficiente de indivíduos que assegure sua perpetuação, e espécies que hoje são numerosas podem vir a se tornar extintas (Heywood et al., 1994); além disso, muitos remanescentes ainda não estão sob influência dos efeitos de borda devido a recente formação do fragmento (Kapos et al. ,1997 e McAlpine et al., 2002). 


\section{MATERIAL E MÉTODOS}

\subsection{Descrição da espécie}

A palmeira Syagrus romanzoffiana (Cham.) Glassm., popularmente conhecida por jerivá, é comumente encontrada na Argentina, Uruguai, Paraguai e nas regiões central e sudeste do Brasil, sendo facilmente encontrada na Floresta Semidecídua do Estado de São Paulo (Henderson et al., 1995). Seus frutos são globosos, com aproximadamente $2,5 \mathrm{~cm}$ de diâmetro e massa 1,62 \pm 0,3 g, com exocarpo macio e endocarpo lenhoso (Galetti et al., 1992 e Fleury \& Galetti, submetido). Esta espécie frutifica durante todo o ano, porém o pico de maturação dos frutos ocorre principalmente nos meses de fevereiro a agosto, produzindo anualmente grande quantidade de sementes viáveis (Otani \& Galetti, dados não publicados).

Os frutos do jerivá são consumidos principalmente por mamíferos, apesar de freqüentemente serem observadas em regurgitações de jacus (Penelope obscura; Guix et al., 2001 e observação pessoal). Antas (Tapirus terrestris) consomem os frutos de $S$. romanzoffiana em grande quantidade, podendo ser encontradas em uma única defecação até 300 sementes desta espécie (Galetti et al., 2001). Macacos prego (Cebus apella), bugios (Alouatta guariba) e esquilos (Sciurus ingrami) também foram observados dispersando e/ou predando sementes desta espécie (Galetti et al.1992; Olmos et al., 1999 e Paschoal \& Galetti, 1995).

A palmeira $S$. romanzoffiana pode ser encontrada praticamente em todas as formações vegetais dos Estados do Espírito Santo, Rio de Janeiro, Minas Gerais, Goiás, Mato Grosso do Sul até o Rio Grande do Sul (Henderson 
et al., 1995). As palmeiras ocorrem em densidade de 15 palmeiras ha- $^{-1}$ nas Florestas Semidecíduas (César \& Leitão Filho, 1990 e Galetti et al.,1992).

\section{2 Áreas de estudo}

\subsubsection{Parque Estadual do Morro do Diabo (MD)}

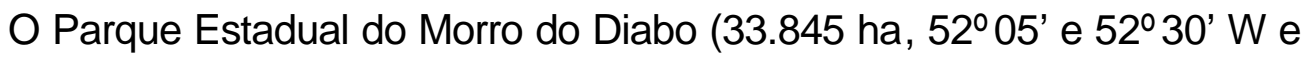
22ำ15' e 2240'S) está localizado na região do Pontal do Paranapanema à margem direita do rio Paranapanema em sua confluência com o rio Paraná, no extremo oeste do Estado de São Paulo. É considerada a reserva de Floresta Mesófila Semidecídua melhor protegida do interior do Estado (Schlitter et al., 1995), sendo raramente registrada a presença de caçadores e outros tipos de pressão antrópica (Cüllen et al., 1999).

O clima da região é, segundo a classificação de Koeppen, do tipo CWA, com chuvas concentradas nos meses de dezembro, janeiro e fevereiro, sendo maio, junho e julho os meses mais secos do ano. A precipitação média anual neste remanescente é de 1.200 mm (Valladares-Pádua, 1987).

As famílias com maior predominância, em percentagem do número de gêneros, espécies e indivíduos são Leguminosae, Euphorbiaceae e Myrtaceae, seguidas por Rutaceae, Lauraceae, Meliaceae e Moraceae, tendo sido amostrados 37 famílias, 85 gêneros e 104 espécies (Schlitter et al., 1995).

A fauna no MD encontra-se bem preservada abrigando mamíferos de grande porte (Cüllen, 1997; Cüllen et al., 2001; Tabela 1). 
Tabela 1. Lista de mamíferos não voadores do Parque Estadual do Morro do Diabo (Cüllen, 1997).

\begin{tabular}{|c|c|}
\hline \multicolumn{2}{|c|}{ PARQUE ESTADUAL DO MORRO DO DIABO (33.845 ha) } \\
\hline Ordem & Espécie \\
\hline \multirow[t]{6}{*}{ DIDELPHIMORPHIA } & Didelphis marsupialis \\
\hline & Didelphis albiventris \\
\hline & Philander opossum \\
\hline & Chironectes minimus \\
\hline & Myrmecophaga tridactyla \\
\hline & Tamandua teradactyla \\
\hline \multirow[t]{4}{*}{ XENARTHRA } & Euphactus sexcintus \\
\hline & Cabassous unicintus \\
\hline & Dasypus novecintus \\
\hline & Dasypus septemcinctus \\
\hline \multirow[t]{4}{*}{ PRIMATES } & Cebus apella \\
\hline & Alouatta guariba \\
\hline & Leonthopithecus chrysopygus \\
\hline & Brachyteles arachnoides \\
\hline \multirow[t]{10}{*}{ CARNIVORA } & Cerdocyon thous \\
\hline & Chysocyon brachyurus \\
\hline & Procyon cancrivorous \\
\hline & Nasua nasua \\
\hline & Galictis vittata \\
\hline & Eira barbara \\
\hline & Lutra longicaudis \\
\hline & Pteronura brasiliensis \\
\hline & Panthera onca \\
\hline & Puma concolor \\
\hline
\end{tabular}


Tabela 1. Lista de mamíferos não voadores do Parque Estadual do Morro do Diabo (Cüllen, 1997).

\begin{tabular}{ll}
\hline PARQUE ESTADUAL DO MORRO DO DIABO (33.845 ha) \\
Herpailurus yaguarondi \\
Leopardus pardalis \\
Leopardus weidi \\
Leopardus tigrinus \\
PERISSODACTYLA & Tapirus terrestris \\
ARTIODACTYLA & Pecari tajacu \\
& Tayassu pecari \\
& Manzama americana \\
& Manzama gouazoubira \\
RODENTIA & Sciurus aestuans \\
& Coendou prehensilis \\
& Hydrochaeris hydrochaeris \\
& Agouti paca \\
& Dasyprocta agouti \\
& Silvilagus brasiliensis \\
\hline
\end{tabular}

\subsubsection{Estação Ecológica dos Caetetus (EEC)}

A Estação Ecológica dos Caetetus (2.178 ha, 4940' e 4944' W e 22ํ2' e 22ํ26'S) está localizada nos Municípios de Gália e Alvinlândia, interior do Estado de São Paulo. Possui uma topografia ondulada em quase toda a sua extensão, abrangendo altitudes que vão desde 500 m a 600 m acima do nível do mar (Cüllen, 1997).

A floresta é do tipo Latifoliada Semidecídua, e exceto a região da borda da mata, que é dominada por lianas e pelo bambu Merostachys spp., a vegetação predominante é de floresta primária com dossel contínuo de 20-25 m 
e ocasionalmente clareiras formadas por quedas de árvores. A EEC possui regiões alagadas com predominância do palmiteiro Euterpe edulis (Olmos et al., 1999).

O clima da região apresenta uma sazonalidade marcante, sendo do tipo CWA segundo Koeppen. A temperatura média anual é de $20^{\circ} \mathrm{C}$, e a precipitação média anual 1.480 mm (Cüllen et al.,1999)

Localiza-se em região altamente desmatada, com pequenos remanescentes florestais de 1 ha a 5 ha, rodeados principalmente por culturas de café, seringais e pastagens (Viana \& Tabanez, 1996), representando um dos principais refúgios para a fauna silvestre (Cüllen, 1997).

A fauna da E. E. dos Caetetus encontra-se preservada, comportando grandes carnívoros e herbívoros (Tabela 2). Foram identificadas também 108 espécies de aves, das quais podemos citar jacu (Penelope obscura), araçariminhoca (Pteroglossus aracari) e araponga (Procnias mudicollis) (Willis \& Oniki, 1991).

Tabela 2. Lista de mamíferos não-voadores da Estação Ecológica dos Caetetus (Cüllen, 1997)

\begin{tabular}{ll}
\hline ESTAÇÃO ECOLÓGICA DOS CAETETUS (2.178 ha) \\
\hline Ordem & Espécie \\
DIDELPHIMORPHIA & Myrmecophaga tridactyla \\
& Tamandua teradactyla \\
XENARTHRA & Euphactus sexcintus \\
& Cabassous unicintus \\
& Dasypus novecintus \\
& Dasypus septemcinctus \\
& Cebus apella \\
PRIMATES & Alouatta guariba \\
& Leonthopithecus chrysopygus \\
\hline
\end{tabular}


Tabela 2. Lista de mamíferos não-voadores da Estação Ecológica dos Caetetus (Cüllen, 1997)

\begin{tabular}{|c|c|}
\hline \multicolumn{2}{|c|}{ ESTAÇÁO ECOLOGGICA DOS CAETETUS (2.178 ha) } \\
\hline & Brachyteles arachnoides \\
\hline \multirow[t]{13}{*}{ CARNIVORA } & Cerdocyon thous \\
\hline & Chysocyon brachyurus \\
\hline & Procyon cancrivorous \\
\hline & Nasua nasua \\
\hline & Galictis vittata \\
\hline & Eira barbara \\
\hline & Lutra longicaudis \\
\hline & Pteronura brasiliensis \\
\hline & Puma concolor \\
\hline & Herpailurus yaguarondi \\
\hline & Leopardus pardalis \\
\hline & Leopardus weidi \\
\hline & Leopardus tigrinus \\
\hline PERISSODACTYLA & Tapirus terrestris \\
\hline \multirow[t]{4}{*}{ ARTIODACTYLA } & Pecari tajacu \\
\hline & Tayassu pecari \\
\hline & Manzama americana \\
\hline & Manzama gouazoubira \\
\hline \multirow[t]{5}{*}{ RODENTIA } & Sciurus aestuans \\
\hline & Coendou prehensilis \\
\hline & Hydrochaeris hydrochaeris \\
\hline & Agouti paca \\
\hline & Dasyprocta agouti \\
\hline LAGOMORPHA & Silvilagus brasiliensis \\
\hline
\end{tabular}




\subsubsection{Fazenda Barreiro Rico - Vivaeiro-Tabatingüera (VT) e Monal (Mo)}

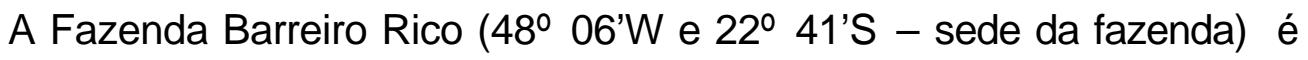
uma propriedade rural criadora de gado, sendo assim a maior fração da fazenda ocupada por pastagens artificiais e, em menor proporção, por monocultura de cana de açúcar. A Fazenda Barreiro Rico está situada no Município de Anhembi, no interflúvio Tietê-Piracicaba. O clima, segundo o sistema de Koeppen, é do tipo CWA, com temperatura média anual de 21,5으. As altitudes variam entre $430 \mathrm{~m}$ (cota máxima da represa de Barra Bonita) e $586 \mathrm{~m}$ (Magalhães, 1999). O trabalho foi conduzido em dois dos três fragmentos pertencentes à Fazenda Barreiro Rico, a Mata do VivaeiroTabatingüera (VT), de 1.471 ha, e Mata do Monal (Mo), de 374 ha. O terceiro fragmento, localizado à esquerda do VT, não foi amostrado por estar situado muito próximo ao $\mathrm{VT}$, e provavelmente sob sua influência.

O fragmento com 1.471 ha comporta animais de grande porte(Tabela 3), porém no fragmento de 374 ha muitos estão localmente extintos (Tabela 4).

Apesar da região ter sido colonizada há muito tempo pela utilização do rio Tietê como via de acesso, a soma dos fragmentos de Floresta Mesófila Semidecídua situados no núcleo Reis-Magalhães (proprietários) é de 2.200 ha, porém a maior extensão dos fragmentos é composta por variados graus de degradação (Magalhães, 1999).

Foram identificados três ambientes distintos floristicamente e fitossociologicamente, determinados principalmente pelas diferentes condições edáficas. Nos pontos mais altos as famílias predominantes são Rutaceae e Melastomataceae e nos mais baixos, Euphorbiaceae e Myrtaceae. As localidades em alturas intermediárias possuem dois tipos de vegetação, Floresta Semidecídua e Cerrado, sendo as famílias Leguminosae e Myrtaceae as mais representativas (Assumpção et al., 1982). Cesar \& Leitão-Filho (1990) 
identificaram 113 espécies de 41 famílias entre as quais as mais abundantes foram Rutaceae, Euphorbiaceae, Rubiaceae, Myrtaceae e Leguminosae.

O represamento do rio Tietê em Barra Bonita em, 1961 inundou totalmente a mata ribeirinha que ocorria ao longo do rio Piracicaba, com áreas de palmito (Euterpe edulis) e cabreutinga (Cyclolobium causeni), esta última provavelmente extinta (Magalhães, 1999).

Tabela 3. Lista de mamíferos não voadores das matas do Vivaeiro Tabatingüera (1.471 ha), fragmento florestal pertencente àFazenda Barreiro Rico.

\begin{tabular}{lll}
\hline & MATA DO VIVAEIRO-TABATINGÜERA (1.471 ha) \\
ORDEM & Espécie & Referência \\
CARNIVORA & Cerdocyon thous & Martins, In Prep. \\
& Nasua nasua & Martins, In Prep. \\
& Herpailurus jagouarundi & Martins, In Prep. \\
& Puma concolor & Martins, In Prep. \\
& Eira barbara & Martins, In Prep. \\
RODENTIA & Dasyprocta sp. & Martins, In Prep. \\
& Agouti paca & Martins, In Prep. \\
XENARTHRA & Hydrochaeris hydrochaeris & Martins, In Prep. \\
& Euphractus sexcintus & Martins, In Prep. \\
& Mazama americana & Martins, In Prep. \\
LAGOMORPHA & Sciurus ingrami & Martins, In Prep. \\
ARTIODACTYLA & Sylvilagus brasiliensis & Observação pessoal \\
& Pecari tajacu & Martins, In Prep. \\
PRIMATES & Mazama americana & Martins, In Prep. \\
& Alouatta guariba & Martins, In Prep. \\
& Brachyteles arachnoides & Assumpção, 1983 \\
& Callicebus personatus & Assumpção, 1983 \\
& Callithrix aurita & Assumpção, 1983 \\
& Cebus apella & Assumpção, 1983 \\
\hline
\end{tabular}


Tabela 4. Lista de mamíferos não voadores da mata do Monal (374 ha), fragmento florestal pertencente àFazenda Barreiro Rico.

\begin{tabular}{lll}
\hline \multirow{2}{*}{ ORDEM } & \multicolumn{2}{c}{ MATA DO MONAL (374 ha) } \\
CARNIVORA & Espécie & Referência \\
& Cerdocyon thous & Martins, In Prep. \\
RODENTIA & Nasua nasua, & Martins, In Prep. \\
& Dasyproctasp. & Martins, In Prep. \\
ARTIODACTYLA & Sciurus ingrami & Martins, In Prep. \\
PRIMATES & Mazama americana & Martins, In Prep. \\
& Cebus apella & Martins, In Prep. \\
& Alouatta guariba & Martins, In Prep. \\
\hline
\end{tabular}

\subsubsection{Mata da Fazenda São José (SJ)}

A mata da Fazenda São José (SJ), de 230 ha, é constituída pela vegetação Mesófila Semidecídua. Está localizada entre os Municípios de Rio

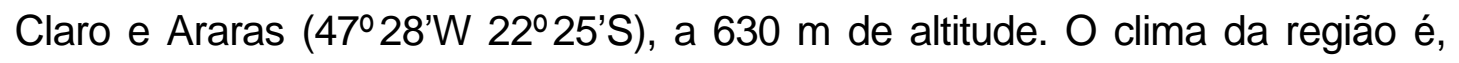
segundo a classificação de Koeppen, do tipo CWA (Pagano, 1987).

A floresta possui contorno irregular circundada por monocultura de cana de açúcar. Possui uma vegetação densa, com dossel entre $15 \mathrm{~m}$ e $30 \mathrm{~m}$ em diferentes locais. A presença de lianas é freqüente, formando densos emaranhados em determinadas áreas. Devido à ação de ventos fortes há clareiras formando grandes aberturas de dossel, ocasionadas por quedas de árvores de grande porte (Pagano, 1987). Muitos dos animais de grande porte já estão localmente extintos, porém ainda possui representantes de primatas e alguns carnívoros (Tabela 5).

$\mathrm{Na}$ região ocorrem dois estratos arbóreos, caracterizados por espécies distintas. O primeiro estrato com maior diversidade de famílias; e o segundo, 
caracterizado por maior diversidade de espécies dentro de cada família (Pagano, 1987).

Tabela 5. Lista de mamíferos não voadores da Mata da Fazenda São José (SJ).

\begin{tabular}{|c|c|c|}
\hline \multicolumn{3}{|c|}{$\begin{array}{l}\text { MATA DA FAZENDA SÃO JOSÉ } \\
\text { (230 ha) }\end{array}$} \\
\hline Ordem & Espécie & Referência \\
\hline \multirow[t]{2}{*}{ XENARTHRA } & Dasypus novemcinctus & Bernardo, 2001 \\
\hline & Euphractus sexcintus & Bernardo, 2001 \\
\hline \multirow[t]{3}{*}{ PRIMATES } & Callithrix aurita & Bernardo, 2001 \\
\hline & Callicebus personatus & Bernardo, 2001 \\
\hline & Cebus apella & Bernardo, 2001 \\
\hline \multirow[t]{7}{*}{ CARNIVORA } & Herpailurus jaguarundi & Bernardo, 2001 \\
\hline & Leopardus pardalis & Bernardo, 2001 \\
\hline & Cerdocyon thous & Bernardo, 2001 \\
\hline & Nasua nasua & Bernardo, 2001 \\
\hline & Procyon cancrivorous & Bernardo, 2001 \\
\hline & Eira barbara & Bernardo, 2001 \\
\hline & Galictis vittata & Bernardo, 2001 \\
\hline ARTIODACTYLA & Mazama americana & Bernardo, 2001 \\
\hline \multirow[t]{7}{*}{ RODENTIA } & Sciurus ingrami & Bernardo, 2001 \\
\hline & Nectomys squamipes & Briani et al, 2001 \\
\hline & Oligoryzomys nigripes & Briani et al, 2001 \\
\hline & Akodon montensis & Briani et al, 2001 \\
\hline & Holochilus brasiliensis & Briani et al, 2001 \\
\hline & Calomys spp. & Briani et al, 2001 \\
\hline & Coendou spp. & Bernardo, 2001 \\
\hline LAGOMORPHA & Sylvilagus brasiliensis & Briani et al, 2001 \\
\hline
\end{tabular}




\subsubsection{Mata do Ribeirão Cachoeira (RC)}

A mata Ribeirão Cachoeira (RC) possui 208 ha e está situada nos subdistritos de Souzas e Joaquim Egídio, porção noroeste do Município de Campinas ( $46^{\circ} 55^{\prime} \mathrm{W}$ e $22^{\circ} 50^{\prime} \mathrm{S}$ ). A Área de Proteção Ambiental em que está inserida apresenta apenas $4,93 \%$ de sua área total ocupada por manchas urbanas; sendo o restante correspondente a áreas agrícolas (8,35\%), de reflorestamento, de fragmentos florestais em diferentes graus de perturbação $(39,25 \%)$ e campos de pastagem $(47,42 \%)$ (Gaspar, 1997).

O clima segundo a classificação de Koeppen é do tipo CWA, com precipitação média anual de $1.409 \mathrm{~mm}$, atingindo $675,4 \mathrm{~mm}$ durante o verão (1ำ de dezembro a 28 de fevereiro) e 117,8 $\mathrm{mm}$ no inverno (10 de junho a 31 de agosto). Ao longo da maior extensão da mata (meridional) corre o ribeirão Cachoeira, um dos mais limpos afluentes do rio Atibaia e um dos principais rios da Bacia do Piracicaba (Gaspar, 1997).

A vegetação é densa, com dossel com $15 \mathrm{~m}$ a $25 \mathrm{~m}$ de altura, sendo comum a ocorrência de indivíduos emergentes com mais de $30 \mathrm{~m}$. Há a ocorrência de lianas por toda a extensão do fragmento florestal, porém de forma mais intensa em pequenas clareiras e ao longo da borda da mata. A mata Ribeirão Cachoeira apresenta nítidos sinais de perturbações naturais e antrópica, como clareiras em diferentes estágios de regeneração e indícios de queimadas em alguns trechos da mata (Gaspar, 1997).

A comunidade de mamíferos da mata Ribeirão Cachoeira é alterada, com extinção local de mamíferos como cateto (Pecari tajacu), queixada (Tayassu pecari), anta (Tapirus terrestris) e cutia (Dasyprocta sp.), porém comporta primatas e carnívoros (Tabela 6). 
Tabela 6. Lista de mamíferos não-voadores encontrados no fragmento florestal Mata do Ribeirão Cachoeira (Gaspar, 1997; dados não publicados).

\begin{tabular}{ll}
\hline & MATA DO RIBEIRAOO CACHOEIRA \\
& (208 ha) \\
\hline Ordem & Espécie \\
PRIMATES & Alouatta guariba \\
& Callithrix aurita \\
& Callithrix jacchus \\
& Cebus apella \\
& Callicebus personatus \\
& Leopardus pardalis \\
CARNIVORA & Puma concolor \\
& Leopardus sp. \\
& Eira barbara \\
RODENTIA & Nasua nasua \\
LAGOMORPHA & Sciurus ingrami \\
\hline
\end{tabular}

\subsubsection{Mata da Pedreira (Pe)}

O fragmento da Mata da Pedreira (13 ha $22^{\circ} 47^{\prime} \mathrm{S}$ e $47^{\circ} 49^{\prime} \mathrm{W}$ ) localizase no Município de Piracicaba, no campus "Luiz de Queiroz" da Universidade de São Paulo, localizado na depressão periférica do Estado de São Paulo. O relevo no local é levemente ondulado, com altitude em torno de 500 metros (Nascimento, 1998). O clima, segundo a classificação de Koeppen é do tipo CWA, com pluviosidade média anual de $1.430 \mathrm{~mm}$ (Departamento de Meteorologia da Esalq - USP). 
A Mata da Pedreira localiza-se às margens do ribeirão Piracicamirim. O remanescente possui um longo histórico de perturbações. Um levantamento de mamíferos não-voadores realizado no campus "Luiz de Queiroz" indica que muitos animais estão localmente extintos, sendo os remanescentes de hábitos generalistas, que se beneficiam em ambientes antropizados (Tabela 6).

\subsubsection{Mata do Pomar (Po)}

A Mata do Pomar (Po) é um fragmento com 9,5 ha de Floresta Estacional Semidecídua localizado no município de Piracicaba $\left(22^{\circ} 42^{\prime} \mathrm{S}\right.$ e $47^{0}$ 37' W), no campus "Luiz de Queiroz" a Universidade de São Paulo. O relevo no local é levemente ondulado, com altitude média de 500 metros (Nascimento, 1998). O clima, segundo a classificação de Koeppen é do tipo CWA, com pluviosidade média anual de $1.430 \mathrm{~mm}$ (Departamento de Meteorologia da Esalq - USP).

A Mata do Pomar tem sofrido ao longo do tempo inúmeros impactos. A partir de um registro cartográfico de 1894 foi possível notar que a Mata do Pomar possuía uma maior área, porém ao longo do tempo foi sendo convertida em cultivos e em instalação dos edifícios da Escola Superior de Agricultura "Luiz de Queiroz" (Catharino, 1989).

Durante as décadas de 60 e 70 a Po sofreu extração de madeira, além de ter ocorrido dois grandes incêndios nas três últimas décadas, sendo o último a aproximadamente 20 anos, o qual resultou em $20-30 \%$ de sua área queimada (Tabanez et al.,1997). A Mata do Pomar caracteriza-se por dominância local de poucas espécies, principalmente zoocóricas e anemocóricas. Nascimento (1998), avaliando as espécies vegetais presentes neste fragmento e relacionando-as com a síndrome de dispersão de sementes, verificou uma diminuição no recrutamento de espécies zoocóricas, inferindo que ao longo do tempo as espécies anemocóricas e autocóricas aumentem de densidade neste 
fragmento. $\mathrm{O}$ autor especula que a diminuição de espécies zoocóricas possa estar relacionada à extinção local de dispersores de sementes. As espécies de pequenos mamíferos correspondem as comumente encontradas em áreas antropizadas, como Rattus rattus, Oligoryzomys nigripes e Calomys tener. São encontradas também espécies introduzidas de outros ecossistemas, como a lebre européia (Leppus spp.) e o sagüi-de-tufo-branco (Callitrix j. jacchus), da região nordeste do Brasil (Tabela 6).

Tabela 7. Lista de mamíferos não-voadores do campus "Luiz de Queiroz", da Universidade de São Paulo (Gheler-Costa, 2002).

\begin{tabular}{ll}
\hline $\begin{array}{l}\text { MAMIFEROS DO CAMPUS “LUIZ DE QUEIROZ” : } \\
\text { MATA DA PEDREIRA (13 ha) } \\
\text { MATA DO POMAR (9,5 ha) }\end{array}$ \\
\hline Ordem & \multicolumn{1}{c}{ Espécie } \\
DIDELPHIMORFIA & Didelphis albiventris \\
& Leotrina crassicaudata \\
XENARTHA & Dasypus novemcinctus \\
PRIMATES & Callithrix j. jacchus \\
CARNIVORA & Cerdocyon thous \\
& Nasua nasua \\
ARTIODACTYLA & Mazama gouazoubira \\
RODENTIA & Coendou prehensilis \\
& Cavia aperea \\
& Hydrochaeris hydrochaeris \\
& Myocastor coypus \\
& Sylvilagus brasiliensis \\
LAGOMORPHA & Leppus spp. \\
&
\end{tabular}




\subsection{Predação de sementes de Syagrus romanzoffiana}

A espécie Syagrus romanzoffiana foi escolhida por ser comumente encontrada nos fragmentos de Floresta Semidecídua do Estado de São Paulo (Lorenzi et al., 1996), por produzir grande quantidade de frutos e pelas palmeiras serem consideradas espécies-chave, ou seja, que sustentam grande parte da biomassa de vertebrados (aves e mamíferos) durante a estação seca ou período de escassez de recursos alimentares (veja Terborgh, 1986 a; b; vanSchaik et al., 1993; porém veja Galetti \& Aleixo, 1998). Para avaliar a taxa de predação das sementes foram testados três microhábitats: clareira, borda e interior de mata.

Frutos maduros de $S$. romanzoffiana foram coletados diretamente de infrutescências, tiveram suas polpas (mesocarpos) manualmente removidas e suas sementes foram depositadas ao solo de forma agrupada, a fim de mimetizar sementes dispersas naturalmente (Galetti et al., 2001). Durante o manuseio dos frutos e sementes foram utilizadas luvas cirúrgicas para o experimento não fosse influenciado pelo odor humano (Duncan et al., 2002).

Como o efeito da densidade de sementes pode variar de acordo com o hábitat, microhábitat, co-ocorrência de outras espécies de sementes, estação, espécie e tipo de predador (Willson \& Whelan, 1990), o número de sementes utilizado por ponto amostral $(n=10)$ foi baseado na quantidade normalmente encontrada dispersa no ambiente por carnívoros e ungulados (Facure \& Giaretta, 1996 e Galetti et al., 2001).

Cada estação experimental constituiu-se de uma parcela contendo 10 sementes nuas, sendo uma marcada com uma carretilha plástica com aproximadamente $10 \mathrm{~m}$ de comprimento de fio de alta resistência, presa à semente por um anel de arame com espessura de $1 \mathrm{~mm}$ (adaptado a partir de Voltolini, 2000). A marcação foi feita para que fosse possível localizá-la e 
verificar, como uma sub amostra, se as sementes removidas haviam sido predadas ou dispersas secundariamente. Cada ponto amostral foi marcado com uma estaca de $20 \mathrm{~cm}$ de comprimento e uma fita rosa fixada nesta, para posterior localização da parcela.

Uma vez que as sementes foram depositadas sem polpa e o único recurso disponível ao animal era o endosperma, tanto as sementes encontradas destruídas por vertebrados quanto as não localizadas foram consideradas predadas (Cintra, 1997 a; b; Hulme, 1994 e Schupp \& Frost, 1989). O endosperma das sementes de palmeiras possui um alto valor nutricional, sendo baixa a probabilidade de dispersão e alta a de predação (Henderson et al., 1995).

As estações exp erimentais de borda de mata foram estabelecidas a aproximadamente $5 \mathrm{~m}$ da matriz adjacente ao fragmento, e os microhábitats florestais, isto é, os pontos amostrados nos interiores de mata e clareiras, foram montados a partir de $100 \mathrm{~m}$ de distância da borda dos fragmentos (Fleury \& Galetti, dados não publicados) distantes $50 \mathrm{~m}$ entre si (Figura 1). Quando encontradas aberturas no dossel foram estabelecidos pontos de clareiras, quando fechado, pontos de interior de mata. Nos remanescentes amostrados foram encontradas baixas densidades de grandes clareiras, sendo assim estabelecidos pontos amostrais de microhábitat de "clareiras" locais com abertura de dossel superiores a $20 \mathrm{~m}^{2}$. 


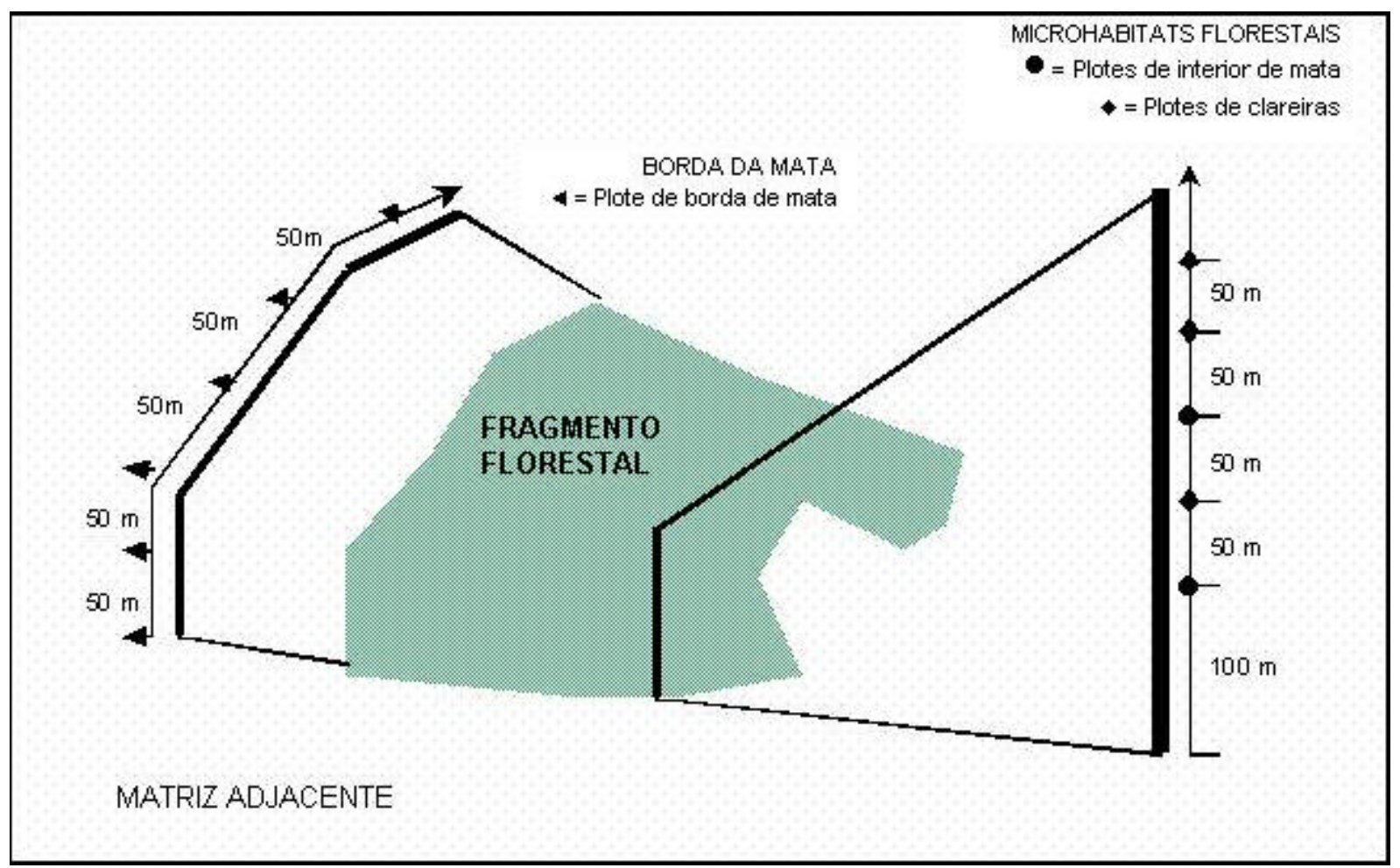

Figura 1 - Diagrama da metodologia utilizada para o estabelecimento dos pontos amostrais nos oito fragmentos de Floresta Semidecídua no Estado de São Paulo.

Foram utilizadas 30 estações por microhábitat no fragmento de maior área (MD - 33.845 ha), 15 estações por microhábitat nos fragmentos com área entre 200 e 3.000 ha (EEC-2.178 ha, VT - 1.451 ha, Mo - 374 ha, RC - 233 ha e SJ - 230 ha) e 5 estações por microhábitat nos fragmentos Po ( 9,5 ha) e Pe (13 ha).

Os experimentos foram conduzidos durante a estação seca de 2001, entre os meses de junho a setembro, nos oito fragmentos florestais amostrados. O procedimento de conduzir os experimentos simultaneamente nos oito fragmentos foi adotado para evitar possíveis variações temporais (Hurlbert, 1984). Os pontos amostrais foram checados após 30 dias após a data de montagem, minimizando a influência da lua na atividade dos pequenos roedores (Bowers \& Dooley, 1993 e Longland \& Price, 1991) e suficiente para a 
observação da predação de sementes pós-dispersas de jerivá ( $S$. romanzoffiana) em Florestas Semidecíduas (Fleury \& Galetti, no prelo) .

\subsection{Caracterização da estrutura dos microhábitats}

As medidas para a caracterização dos microhábitats foram tomadas no trigésimo dia, sendo uma etapa subseqüente aos experimentos de predação de sementes. Para a caracterização da estrutura dos microhábitats foram selecionadas as variáveis que pudessem exercer alguma influência no acesso dos predadores às estações experimentais, e as que qualificassem o ambiente para pequenos e médios roedores de $S$. romanzoffiana, principais predadores de sementes (Paschoal \& Galetti, 1995).

O método de amostragem utilizado foi adaptado a partir do empregado por J. L. García-Castaño (dados não publicados) para caracterização de microhábitats na Região Mediterrânea (Figura 2). Todas as observações realizadas foram feitas pelo mesmo observador visando a padronização do erro. Em cada estação experimental de cada fragmento foi observado:

em um raio de $5 \mathrm{~m}$ em relação ao ponto central da estação experimental, se a palmeira Syagrus romanzoffiana era presente ou não. Se presente, se estava em período de frutificação ou não.

- $\quad$ em um raio de $5 \mathrm{~m}$ em relação ao ponto central da estação experimental, se havia outra espécie frutificando que pudesse representar um recurso atrativo;

- $\quad$ em um raio de 5 metros em relação ao ponto central da estação experimental, se havia ou não tronco caído, liana herbácea e liana lenhosa;

- $\quad$ em uma circunferência com raio de meio metro em relação ao ponto central da estação experimental, foram estimadas as 
coberturas vegetais em três planos: (1) de $0 \mathrm{~m}$ a $0,5 \mathrm{~m}$ e (2) de 0,5 m a 1,0 m estimadas visualmente; e (3) acima de $1 \mathrm{~m}$ com a utilização de um densiômetro. Os três planos de altura foram considerados independentes, sem a consideração das demais alturas;

para os mesmos intervalos de altura, (1) de $0 \mathrm{~m}$ a $0,5 \mathrm{~m}$, (2) de 0,5 $\mathrm{m}$ a $1,0 \mathrm{~m}$ e (3) acima de $1 \mathrm{~m}$, foram medidas as distâncias do ponto amostral até a estrutura lenhosa mais próxima com diâmetro superior a $1 \mathrm{~cm}$;

- o elemento que se localizava mais próximo da estação experimental. Para inserir esta variável na análise estatística, os elementos foram codificados como (1) liana lenhosa; (2) liana herbácea; (3) caule; (4) tronco de árvore caída ou (5) gramíneas. 


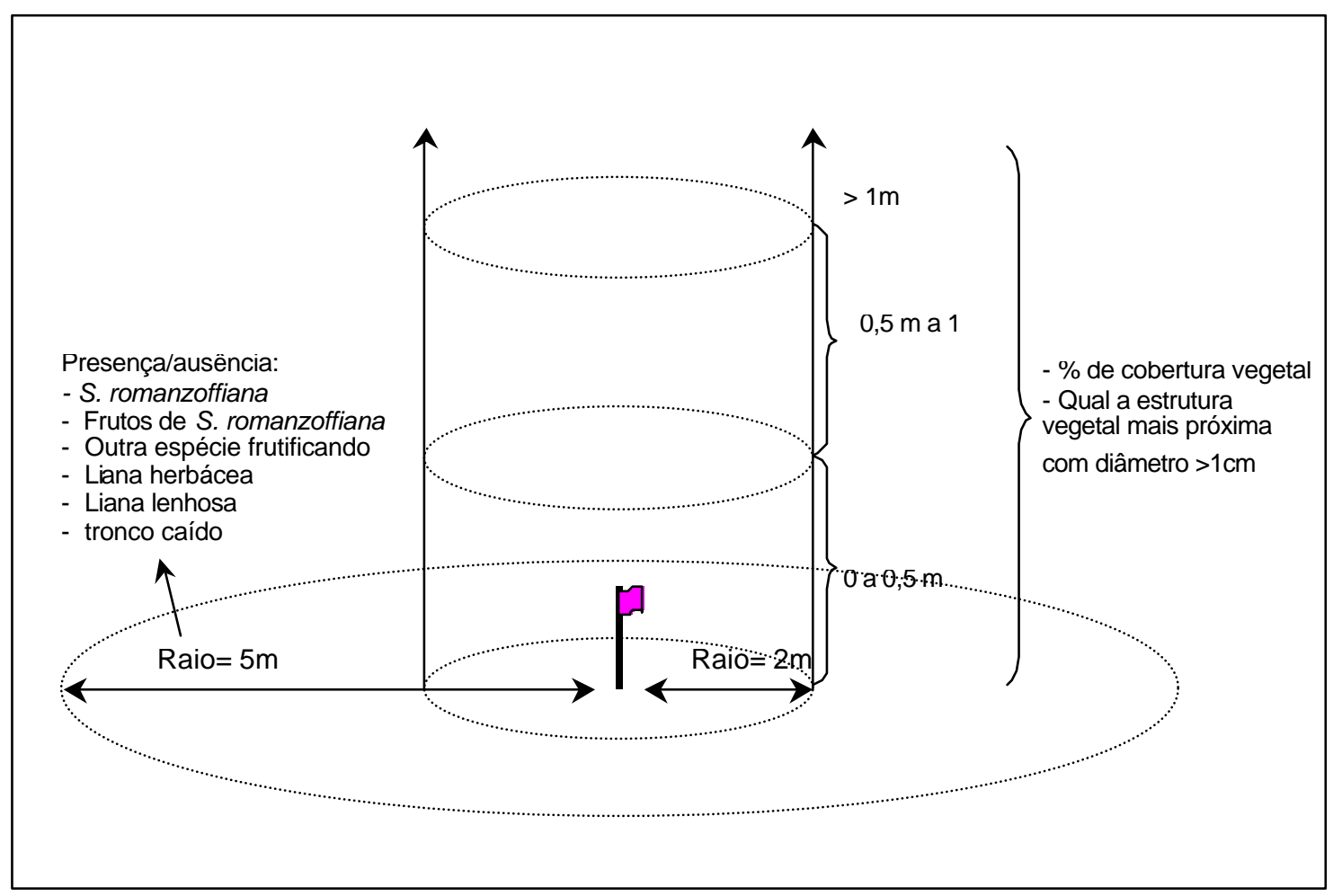

Figura 2 - Metodologia empregada para o levantamento das características estruturais de vegetação dos microhábitats de borda, interior de mata e clareira, aplicado em cada estação experimental dos oito fragmentos avaliados (MD, EEC, VT, Mo, SJ, RC, Pe e Po).

Além das características estruturais, as abundâncias de esquilos e a diversidade de mamíferos de grande porte foram classificadas de 0 a 3 para os oito fragmentos florestais. As classes foram obtidas a partir de levantamentos encontrados na literatura ou de dados não publicados Os esquilos foram incluídos por serem importantes predadores de sementes de $S$. romanzoffiana (Galetti et al., 1997 e Otani \& Galetti, dados não publicados), e mamíferos de grande porte por agirem ou diretamente como predadores de sementes, como 
os porcos do mato (Pecari tajacu e Tayassu pecari, Forget, 1996), ou por exercerem pressão nas comunidades de pequenos e médios roedores, como os médios e grandes carnívoros (Fonseca \& Robinson, 1990).

Para cada fragmento amostrado foi calculado o índice de forma ("Shape Index" - SI, sensu Patton, 1975 e modificado por Laurance, 1991 e Laurance \& Yensen, 1991). O SI foi calculado no Idrisi 2.0 a partir da área total do fragmento (TA), do comprimento total do perímetro $(P)$, obtidos através de imagens do satélite Landsat 7 para os fragmentos 33.845 ha (MD), 2.178 ha (EEC), 1.471 ha (VT), 374 ha (Mo) e 230 ha (SJ), e fotos aéreas dos fragmentos 208 ha $(\mathrm{RC}), 13$ ha $(\mathrm{Pe})$ e 9,5 ha $(\mathrm{Po})$, georreferenciadas no mesmo programa. O valor de $S I$ oscila entre 1 , para forma circular perfeita, e valores superiores a 8 para fragmentos de formato muito irregular. $O$ fragmento com alto valor de $S /$ possui maior quantidade de área sob influência do efeito de borda do que outro remanescente com mesma área porém com um menor perímetro, e conseqüentemente, com $S /$ mais baixo. A fórmula para Slé dada por:

$$
S I=\frac{P}{200\left[(\pi T A)^{0.5}\right]},
$$

Onde:

$\mathrm{P}=$ perímetro do fragmento florestal $(\mathrm{m})$

$\mathrm{TA}=$ área total do fragmento florestal $\left(\mathrm{m}^{2}\right)$ 


\subsubsection{Análise estatística}

As variáveis estruturais de ausência ou presença foram codificadas como 0 (zero) e 1 (um) respectivamente. A identificação de qual o elemento que se localizava mais próximo dos pontos centrais das estações onde foram conduzidos experimentos de predação de sementes de $S$. romanzoffiana foram codificadas nas 5 categorias descritas no item 3.2; e as distâncias dos elementos mais próximos para os três intervalos de altura (de $0 \mathrm{~m}$ a 0,5 m, de $0,5 \mathrm{~m}$ a $1 \mathrm{~m} \mathrm{e}>1 \mathrm{~m}$ ) ao ponto central foram transformadas em 6 classes de intervalos (Tabela 8), por existirem estações em que o elemento mais próximo se localizava a uma distância superior a 0,5 m.

Tabela 8. Classes dos intervalos de distância do ponto amostral àestrutura mais próxima.

\begin{tabular}{cc}
\hline Intervalo de distância & Classe \\
\hline $0 \neg 0,1 \mathrm{~m}$ & 1 \\
$0,1 \mathrm{~m} \neg 0,2 \mathrm{~m}$ & 2 \\
$0,2 \mathrm{~m} \neg 0,3 \mathrm{~m}$ & 3 \\
$0,3 \mathrm{~m} \neg 0,4 \mathrm{~m}$ & 4 \\
$0,4 \mathrm{~m} \neg 0,5 \mathrm{~m}$ & 5 \\
$>0,5 \mathrm{~m}$ & 6 \\
\hline
\end{tabular}


Antes de proceder com a análise multivariada, as variáveis estruturais foram comparadas entre os fragmentos para que fossem avaliados quais eram significativas ao modelo, utilizando o Teste $G$, da razão da verossimilhança. Somente a presença/ausência de frutos de $S$. romanzoffiana foi excluída do modelo por possuir a freqüência muito baixa em todos os microhábitats de todos fragmentos.

Para a análise das características de microhábitat foi utilizada a análise de ordenação MDS, o Escalonamento Multidimensional não-métrico, por ser insensível a não normalidade e a multicolinearidade (Legendre \& Legendre, 1998). Para evitar possíveis vieses, no MDS não foram inseridas as variáveis de taxa de predação de sementes de $S$. romanzoffiana, de abundância de esquilos, de presença de mamíferos de grande porte, as áreas dos fragmentos nem seus Sk, sendo utilizadas somente as variáveis de caracterização dos microhábitats. Para cada ponto as variáveis inseridas no modelo MDS foram: moda das freqüências de outras espécies frutificado, troncos caídos, lianas herbáceas e lenhosas, distância do elemento mais próximo com diâmetro superior a $1 \mathrm{~cm}$ nos três intervalos de altura $(0$ a 0,5 m, 0,5 a $1 \mathrm{~m}$ e acima de $1 \mathrm{~m})$ e da categoria de qual o elemento mais próximo æ̀s sementes, e a média da cobertura vegetal nos três intervalos de altura.

A análise MDS foi realizada no pacote estatístico 'Le Progiciel R - 4.0 ' (Casgrain \& Legendre, 2001), com as médias das variáveis quantitativas e com as modas das variáveis qualitativas, das classes e das categorias para os três microhábitats para cada fragmento. Este procedimento resultou em uma tabela com 24 linhas com 11 variáveis (colunas), que antes de proceder com o MDS foi convertida em uma matriz de similaridade $\left(S_{i j}\right)$ e posteriormente convertida em uma matriz de distância $\left(D_{i j}\right)$ pela fórmula:

$$
D_{i j}=\sqrt{1-S_{i j}} \text {, }
$$

Onde:

$$
\begin{aligned}
& S_{i j}=\text { matriz de similaridade } \\
& D_{i j}=\text { matriz de distância }
\end{aligned}
$$


Para a validação do modelo MDS foi utilizado o diagrama de Shepard, os autovetores fornecidos pelo modelo foram inseridos em um gráfico de dispersão para a interpretação dos resultados. Os autovalores gerados pelo modelo MDS foram inseridos com todas as variáveis, incluindo as não introduzidas no MDS, permutadas 10.000 vezes, e analisadas através da Correlação de Spearman (Casgrain \& Legendre, 2001). 


\section{$4 \quad$ RESULTADOS}

\subsection{Predação de sementes de Syagrus romanzoffiana}

A taxa de predação de sementes de Syagrus romanzoffiana diferiu entre os fragmentos florestais $\left.\alpha^{2}=157.95, p<0.0001\right)$, sendo encontradas as maiores taxa de predação nos fragmentos com 374 ha e 230 ha (Figura 3).

No maior remanescente florestal, com 33.845 ha, a predação de sementes foi baixa em todos os microhábitats. Somente $6,33 \%$ das sementes foram removidas, sendo dessas $56,14 \%$ no interior de mata, $33,33 \%$ nas clareiras e $10,53 \%$ na borda da mata, com o padrão de predação diferindo significativamente entre os microhábitats $\left(\chi^{2}=20,73 ; p<0,0001\right)$. 


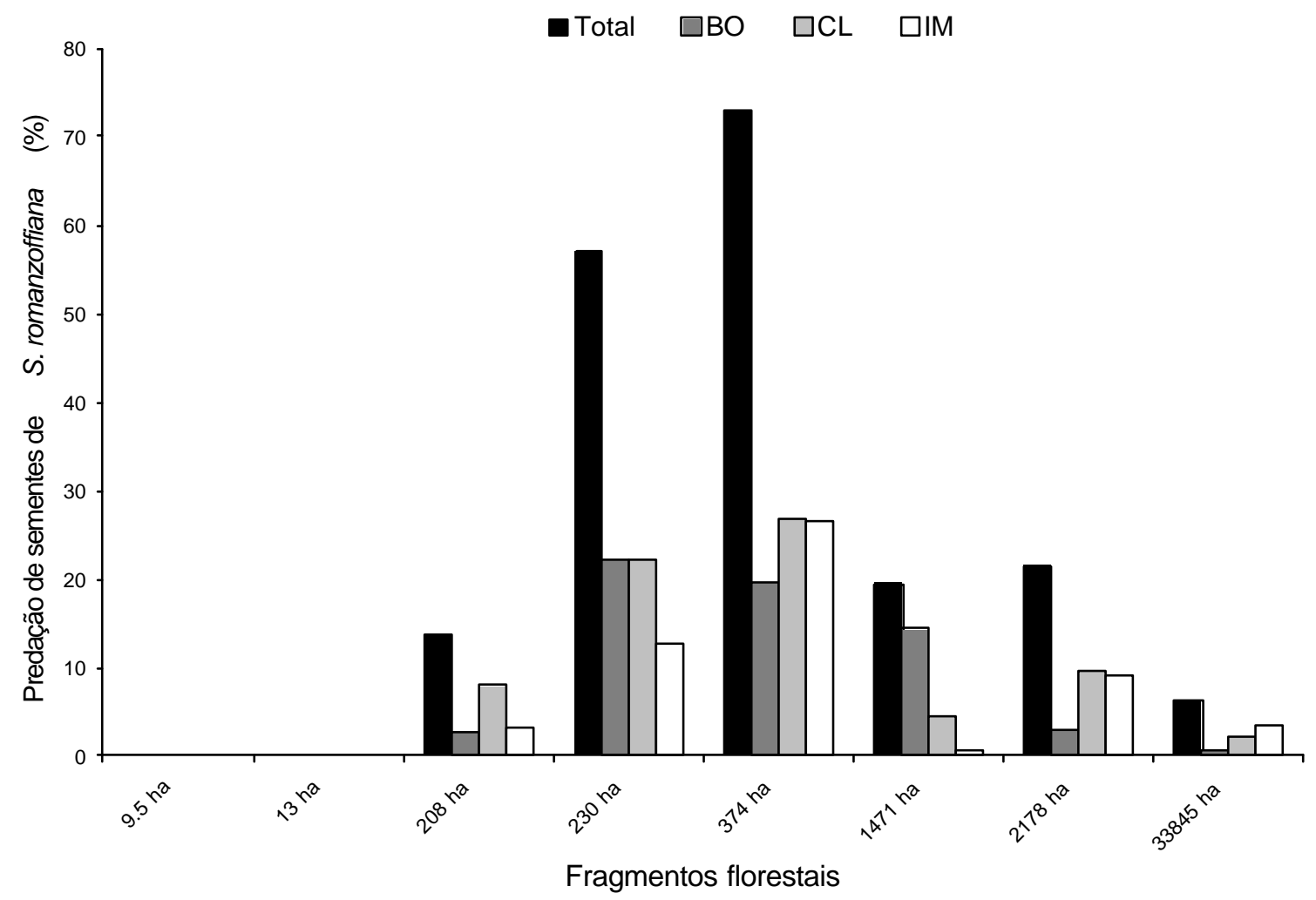

Figura 3 - Percentagem total de sementes de Syagrus romanzoffiana predadas (preto), e percentagem relativa nos três microhábitats amostrados, borda (BO, cinza escuro), clareira (CL,cinza) e interior de mata (IM, branco) nos oito fragmentos de Floresta Semidecídua amostrados. 
Em algumas das estações experimentais de interior de mata do fragmento com 33.845 ha foram encontrados indícios de que cateto (Pecari tajacu) e/ou queixada (Tayassu pecari) haviam visitado o local, como o pisoteamento de plântulas, serrapilheira revolvida e raízes expostas com marcas de dentes. Em uma das estações experimentais de interior de mata a marcação da semente foi localizada destruída, sem a semente presa a esta, provavelmente expelida após a mastigação (Figura 4). Na borda da mata foram encontradas sementes predadas por pequeno roedor (Figura 5).

A taxa de predação de sementes no fragmento florestal de 2.178 ha diferiu entre os microhábitats $\left(\chi^{2}=24,97 ; p<0,0001\right)$, com $21,56 \%$ do total de sementes predadas. Do total de sementes predadas neste fragmento, a percentagem na borda da mata foi de $13,40 \%$, porém uma maior proporção de consumo foi encontrada em ambientes florestais, com $44,33 \%$ em clareiras e $42,27 \%$ no interior de mata. Já na área com 1.471 ha, 19,56\% das sementes de S. romanzoffiana foram removidas, sendo a maior percentagem de predação encontrada na borda da mata $(73,86 \%)$, do que nos microhábitats de clareira $(22,73 \%)$ e interior de mata $(3,41 \%)\left(\chi^{2}=92,28 ; p<0,0001\right)$.

No remanescente florestal com 374 ha, 73,11\% das sementes foram removidas, sendo consumida em menor percentagem na borda da mata $(26,75 \%)$, que nos microhábitats de clareira e no interior de mata $(36,78 \%$ e $36,47 \%$ respectivamente; $\left.\chi^{2}=23,09 ; p<0,0001\right)$. No fragmento com 230 ha, $57,11 \%$ das sementes foram predadas, e assim como no remanescente com 374 ha, a predação foi mais intensa nos microhábitats de interior de mata e clareiras $(39,0 \%$ em cada microhábitat), diferindo da borda da mata $(22,0 \%$; $\left.\chi^{2}=33,57 ; \mathrm{p}<0.0001\right)$. Em ambos fragmentos todas as sementes predadas localizadas, sem exceção, possuíam marcas características de predação por esquilo (Figura 6). Os esquilos mordem a semente em formato triangular no lado oposto à invaginação interna do endocarpo, consumindo assim o endosperma da semente (Henderson et al., 1995). 
O remanescente florestal com 208 ha obteve $22,58 \%$ de suas sementes removidas, com percentagens similares entre os microhábitats de borda $(19,95 \%)$ e interior de mata $(22,58 \%)$, e com maior taxa nos pontos de clareiras $\left(58,06 \% ; \chi^{2}=18,81 ; p<0,0001\right)$.

Nas estações experimentais dos microhábitats de interior de mata e clareiras dos fragmentos florestais de 13 ha e 9,5 ha as sementes de $S$. romanzoffiana foram removidas a poucos centímetros do local onde haviam sido primariamente depositadas, tendo sido quase todas, exceto uma no $\mathrm{Pe} e$ duas no Po, localizadas intactas. Portanto, as sementes não localizadas não foram consideradas predadas. A região de Piracicaba possui a maior população mundial de capivaras (Hydrochaeris hydrochaeris), e apesar de esses animais usualmente se deslocarem por trilhas, os machos possuem 0 comportamento territorialista de marcação anal em plântulas e ramos com altura similar à estacas utilizadas para marcação da estação experimental (15 a $20 \mathrm{~cm}$ ). Todos os pontos onde as sementes foram removidas a curtas distâncias foram evidentemente pisoteados pelas capivaras (K. Ferraz, comunicação pessoal). Nos demais fragmentos todas as sementes removidas foram evidentemente predadas, não tendo sido observadas remoções secundárias. Do total das sementes encontradas predadas em todos os fragmentos florestais amostrados, $3 \%$ por catetos (Pecari tajacu) e/ou queixadas (Tayassu pecari) (Figura 4), 1\% por pequenos roedores (Figura 5) e $96 \%$ foram evidentemente predadas por esquilos (Figura 6 ). 


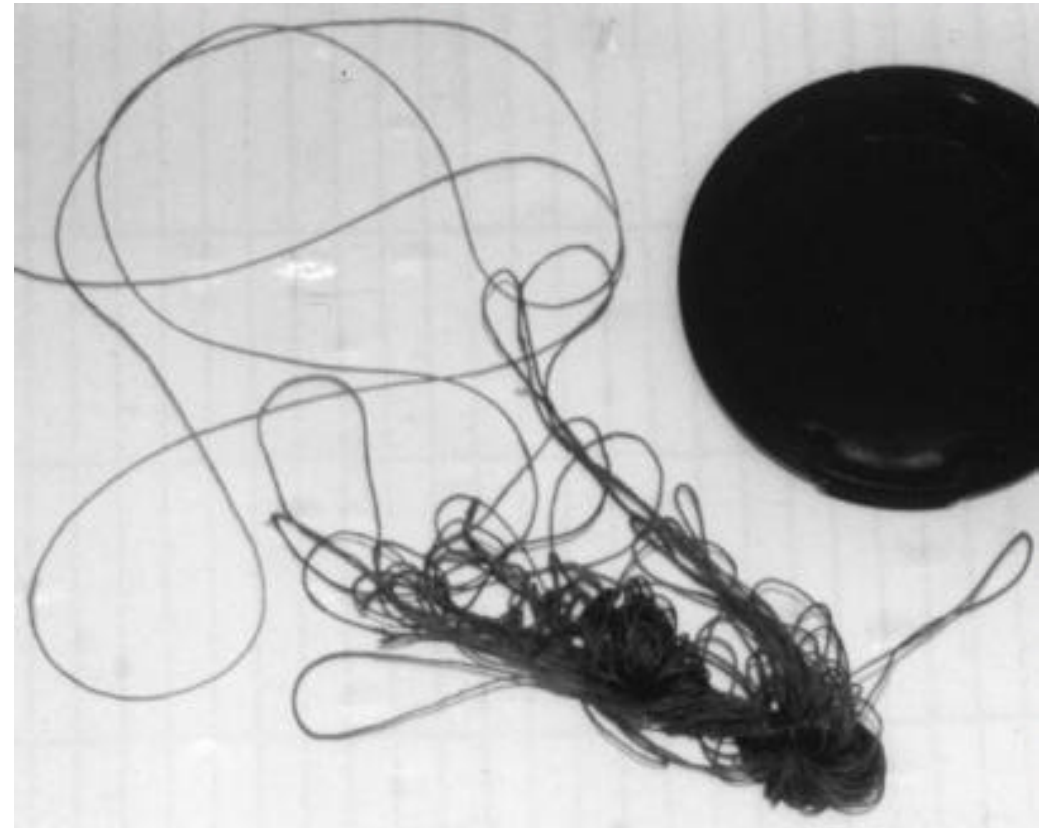

Figura 4 - Semente de Syagrus romanzoffiana predada por cateto (Pecari tajacu) e/ou queixada (Tayassu pecari)
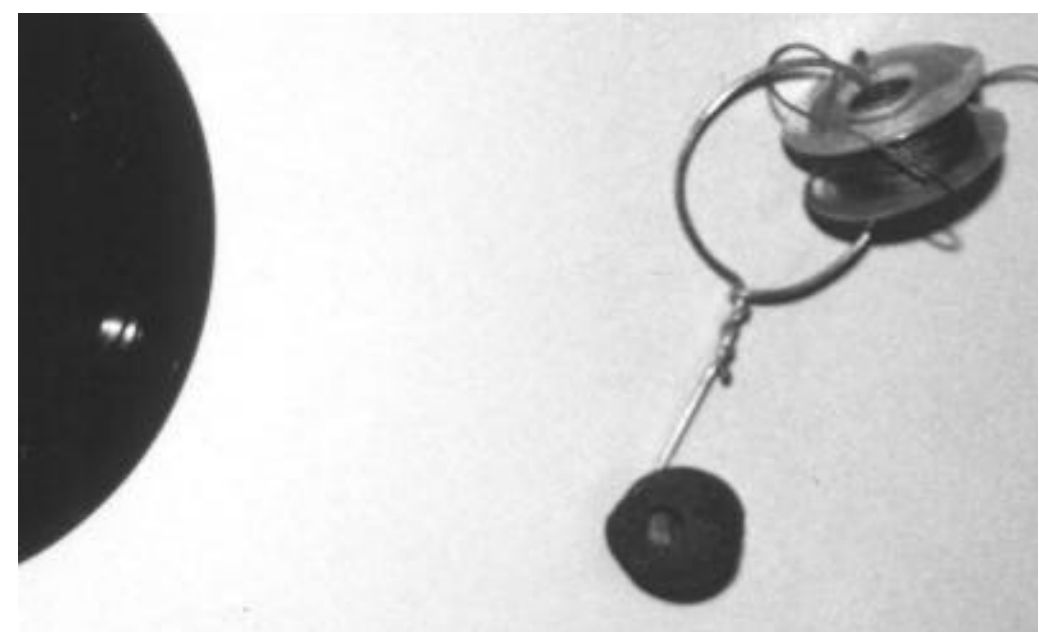

Figura 5 - Semente de Syagrus romanzoffiana predada por pequeno roedor. 


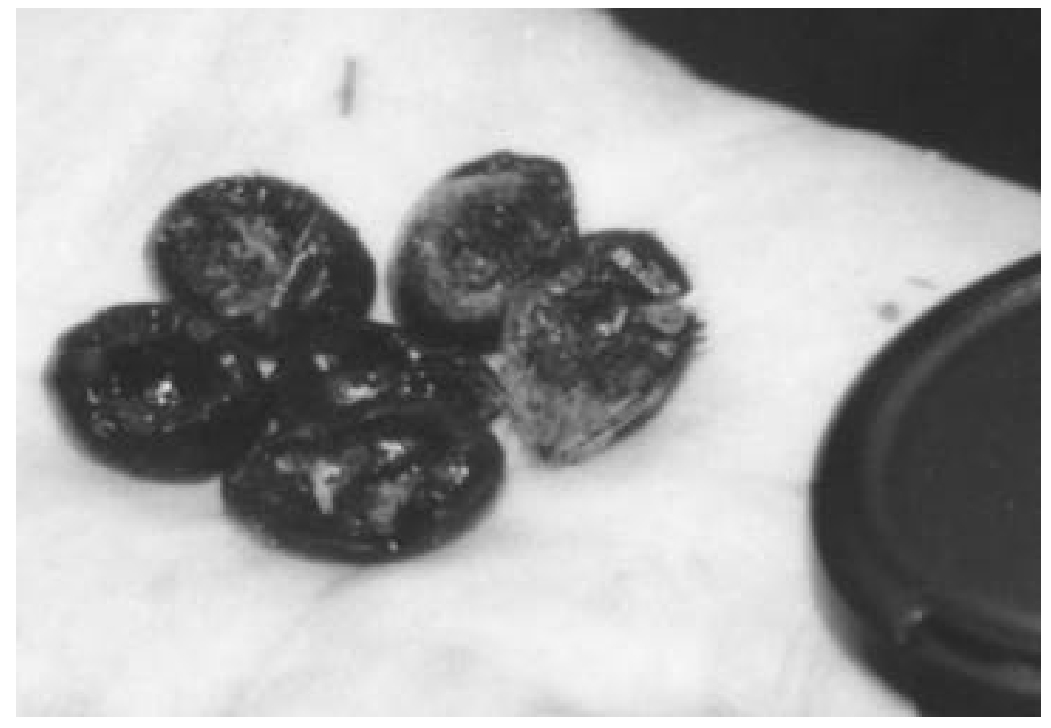

Figura 6 - Sementes de Syagrus romanzoffiana predada por esquilo (Sciurus ingrami).

\subsection{Características da estrutura dos microhábitats}

O número de estações amostradas foi suficiente, cobrindo a variação dos dados (Teste $\mathrm{G}$ da razão da verossimilhança; $\chi^{2}=305,7128 ; \mathrm{P}<0,0001$ ). $\mathrm{O}$ modelo gerado pelo MDS foi validado pelo Diagrama de Shepard (Figura 3), que segundo Casgrain \& Legendre (2001) é considerado ajustado se apresentar os pontos próximos ou acima da linha diagonal do diagrama. 


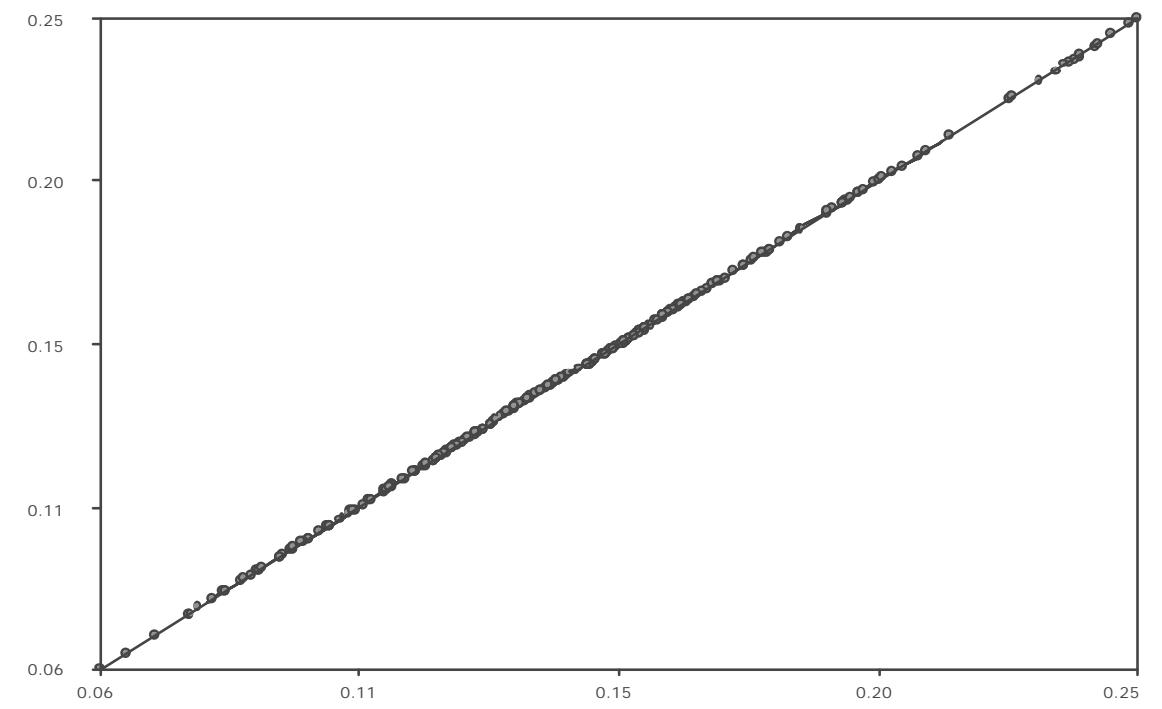

Figura 7 - Diagrama de Shepard para a validação do modelo de Escalonamento Multidimensional não métrico, gerado com as variáveis estruturais dos microhábitats de borda, interior de mata e clareira nos oito fragmentos de Floresta Semidecídua testados. 
Tabela 9. Índice de forma $(S I)$ dos fragmentos MD (Parque Estadual do Morro do Diabo), EEC (Estação Ecológica dos Caetetus), VT (Mata do Vivaeiro Tabatingüera), Mo (Mata do Monal), SJ (Mata São José), RC (Mata do Ribeirão Cacheira), Pe (Mata da Pedreira) e Po (Mata do Pomar).

\begin{tabular}{ccc}
\hline Fragmento & Tamanho (ha) & Indice de Forma (S) \\
\hline MD & 33.845 & 2,529 \\
EEC & 2.178 & 2,12 \\
VT & 1.471 & 2,896 \\
Mo & 374 & 2,384 \\
SJ & 230 & 2,403 \\
RC & 208 & 1,409 \\
Pe & 13 & 2,63 \\
Po & 9,5 & 1,48 \\
\hline
\end{tabular}




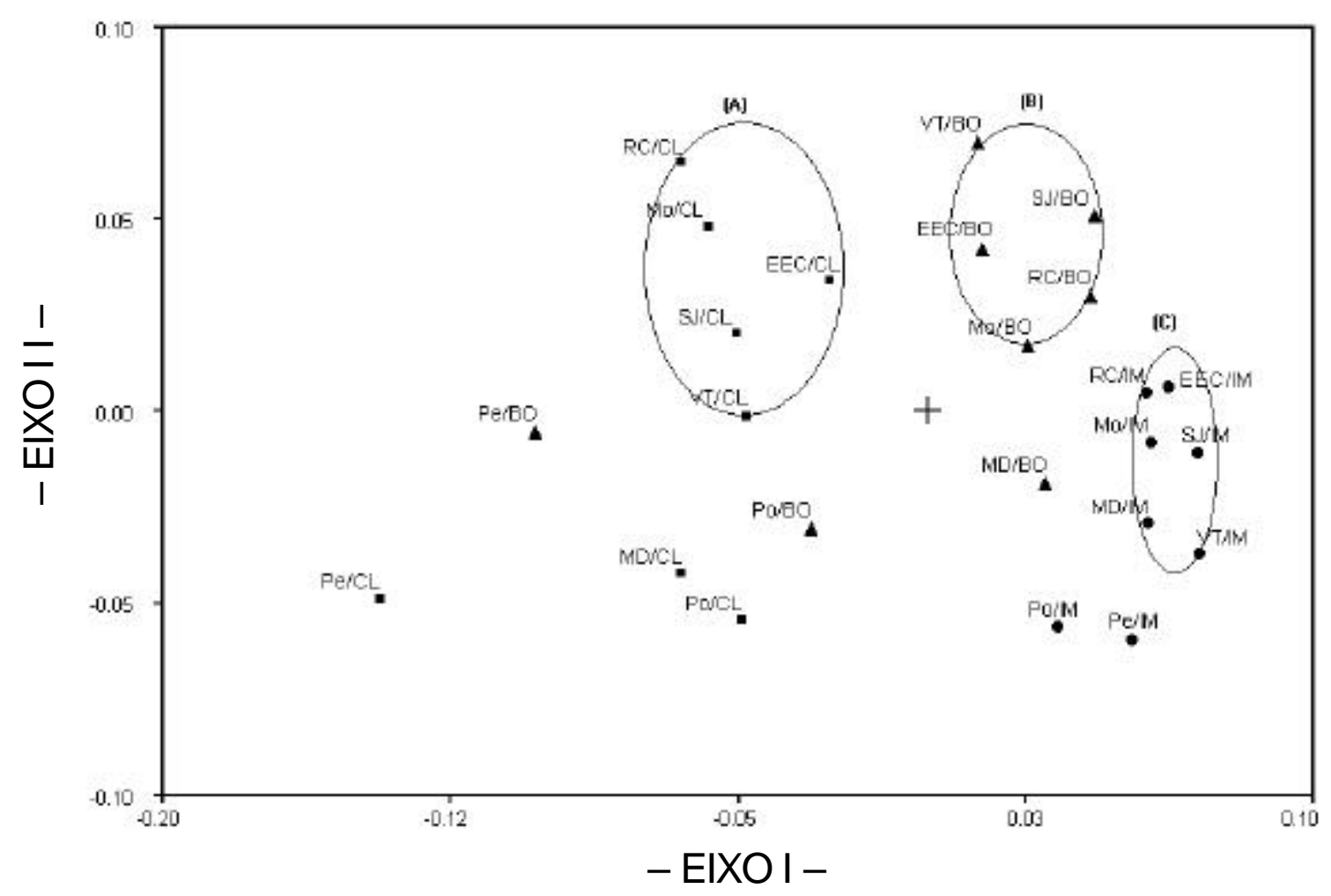

Figura 8 - Dispersão dos valores dos autovetores gerados pela análise de escalonamento multidimensional não métrico (MDS) com as variáveis estruturais dos microhábitats de borda $(=\mathrm{BO})$, interior de mata $(\bullet=$ IM) e clareira $(\mathbf{\square}=\mathrm{CL})$ nos oito fragmentos de Floresta Semidecídua (Po, Pe, RC, SJ, Mo, VT, EEC e MD). As formas elipsóides são os agrupamentos de $(A)$ clareira, $(B)$ borda e $(C)$ interior de mata.

O gráfico de dispersão dos valores dos autovetores gerados pelo MDS determinou três agrupamentos, formados a partir das semelhanças entre os pontos, determinadas pelas variáveis inseridas no modelo (Figura 6). Os autovalores gerados pelo modelo MDS apresentaram correlação positiva com o tamanho do fragmento (Correlação de Spearman; $r^{2}=0,8364 ; p=0,0001$ ) e com a presença de representantes de mamíferos de grande porte na área $\left(r^{2}=\right.$ $0,5102 ; p=0,0001)$. 
A maior diversidade de mamíferos de grande porte esteve correlacionada com os maiores fragmentos $\left(r^{2}=0,4755 ; p=0,0001\right)$ com a presença de lianas lenhosas $\left(r^{2}=0,4345 ; p=0,0422\right)$, com altas percentagens de cobertura vegetal acima de $1,0 \mathrm{~m}\left(r^{2}=0,3919 ; p=0,0302\right)$, com menores distâncias das estruturas com diâmetro superior a $1,0 \mathrm{~cm}$ para os intervalos de altura de 0 a $0,5 \mathrm{~m}\left(\mathrm{r}^{2}=-0,4839 ; \mathrm{p}=0,0058\right)$ e de 0,5 a $1,0 \mathrm{~m}\left(\mathrm{r}^{2}=-0,4554 ; \mathrm{p}=\right.$ 0,0126).

A predação de sementes de S. romanzoffiana foi mais intensa em pontos com maiores percentagens de cobertura vegetal no intervalo de $0,5 \mathrm{~m}$ a $1 \mathrm{~m} \quad\left(r^{2}=0,52 ; p=0,006\right)$ e em ambientes com maior presença de lianas lenhosas $\left(r^{2}=0,27 ; p=0,0351\right)$, diminuindo em pontos com maiores distâncias do ponto amostral ao elemento lenhoso com diâmetro $>1 \mathrm{~cm}$ para 0 intervalo de 0 a $0,5 \mathrm{~m}$ de altura $\left(r^{2}=-0,37 ; p=0,023\right)$. A abundância de Sciurus ingrami esteve fortemente correlacionada com a predação de sementes de $S$. romanzoffiana, sendo as maiores taxas de predação localizadas nos fragmentos com as maiores abundâncias $\left(r^{2}=0,71 ; p=0,0004\right)$, correspondendo aos ambientes do agrupamento $C$ do gráfico de dispersão (Figura 6 ).

A maior freqüência de lianas lenhosas foram encontradas em locais com maiores percentagens de cobertura vegetal acima $1 \mathrm{~m}\left(r^{2}=0,7476 ; p=\right.$ $0,0034)$, locais que associados a ambientes com alta abundância de esquilos $\left(r^{2}\right.$ $=0,4345 ; p=0,0185)$ e ambientes que ainda possuem representantes de mamíferos de grande porte $\left(r^{2}=0,4345 ; p=0,0424\right)$.

Os locais com maior freqüência de liana lenhosa corresponderam a pontos com menores distâncias da estação experimental a uma estrutura com diâmetro superior a $1 \mathrm{~cm}$ para intervalo de $0 \mathrm{~m}$ a $0,5 \mathrm{~m}\left(\mathrm{r}^{2}=-0,4684 ; p=0,05\right)$, mas com baixas percentagens de cobertura vegetal no intervalo 0 a $0,5 \mathrm{~m}\left(r^{2}=-\right.$ 0,$647 ; p=0,0073$ ), ambientes que determinaram o agrupamento $B$ (Figura 6 )

A maior freqüência de troncos caídos foi encontrada em ambientes com altas percentagens de cobertura vegetal no intervalo de 0 a $0,5 \mathrm{~m}$ de altura $\left(\mathrm{r}^{2}=\right.$ 0,$4263 ; p=0,0167$ ), com baixas percentagens de cobertura vegetal acima de 
$1 \mathrm{~m}\left(r^{2}=-0,4262 ; p=0,0168\right)$ e com menor densidade de estruturas com diâmetro superior a $1 \mathrm{~cm}$ acima de $0,5 \mathrm{~m}$ (no intervalo de $0,5 \mathrm{~m}$ a $1 \mathrm{~m} \mathrm{r}^{2}=$ 0,$4417 ; p=0,0159$; acima de $1 \mathrm{~m} \mathrm{r}^{2}=0,6763 ; p=0,0001$ ). Estas características constituíram os locais com as menores abundâncias de esquilos $\left(r^{2}=-0,3883\right.$; $p=0,0424)$. Estes ambientes correspondem aos que determinaram 0 agrupamento A do gráfico de dispersão dos autovalores (Figura 6).

A área do fragmento florestal apresentou correlação positiva com maior diversidade de mamíferos de grande porte $\left(r^{2}=0,4755 ; p=0,0001\right)$, porém não esteve diretamente relacionada com a abundância de esquilos $\left(r^{2}=-0,0582 ; p=\right.$ $0,413)$, mas sim com a diversidade de mamíferos de grande porte $\left(r^{2}=-0,3883\right.$; $p=0,0442$ ).

Os fragmentos mais irregulares, ou seja, com maiores valores de $S I$, correspondeu aos remanescentes de maior diversidade de representantes de mamíferos de grande porte $\left(r^{2}=-0,3881 ; p=0,0302\right)$. Os valores de $S /$ não apresentaram correlação com o tamanho da área dos remanescentes florestais $\left(r^{2}=0,2503 ; p=0,1204\right)$. 


\section{DISCUSSÃO}

\subsection{Predação de sementes de Syagrus romanzoffiana}

Não houve dispersão secundária, sendo todas as sementes removidas localizadas evidentemente predadas, concordando com a hipótese de Schupp \& Frost (1989).

Corroborando com estudos previamente registrados na literatura os esquilos Sciurus ingrami (caxinguelês ou serelepes) foram os principais predadores de S. romanzoffiana (Bordignon et al., 1996, Galetti et al., 1992; Olmos et al., 1999, Paschoal \& Galetti, 1995), estando a sobrevivência de suas sementes intimamente associada à distribuição e abundância dos esquilos (Emmons \& Gentry, 1983). Os esquilos possuem um padrão de predação de semente característico, abrindo um orifício de formato triangular no lado oposto a invaginação interna do endocarpo, consumindo assim o endosperma da semente (Galetti et al., 1992).

As áreas superiores a 1000 ha, os fragmentos 33.845 ha, 2.178 ha e 1.471 ha, a predação de sementes de $S$. romanzoffiana ocorreu de forma diferenciada entre os microhábitats. Nestes fragmentos existe maior heterogeneidade vegetal, com locais em diferentes estágios sucessionais ao longo do remanescente, de forma que a comunidade animal responde a esses diferentes ambientes (Emmons, 1982) e conseqüentemente, as taxas de predação ocorrem também de maneira heterogênea, variando de acordo com o microhábitat (Peña-Claros \& deBoo, 2002). 
Lurz et al. (1997) avaliando os efeitos espaço-temporal na qualidade de hábitat de Sciurus vulgaris verificou que em ambientes estáveis, como fragmentos com grandes áreas, os esquilos são fiéis ao hábitat devido à ausência de sazonalidade na oferta de alimentos. A alta predação na borda da mata do fragmento com 1.471 ha pode estar associada com o fato de terem sido observadas espécie frutificando somente neste microhábitat. Nos maiores fragmentos amostrados, 33.845 ha, 2.178 ha e 1.471 ha, além dos S. ingrami, estão presentes mamíferos de grande porte que são importantes predadores de sementes, como o cateto e o queixada (Pecari tajacu e T. pecari; Forget, 1996).

O fragmento florestal com 208 ha apresentou uma menor taxa de predação de sementes quando comparado com os fragmentos com áreas semelhantes, com 230 ha e 374 ha. Danielson et al. (1997) verificou que fragmentos urbanos podem possuir menor remoção que os rurais, e o remanescente com 208 ha situa-se em um condomínio residencial, ao passo que os de 230 ha e 374 ha estão localizados em áreas de pastagens e canaviais.

Os fragmentos com 9,5 ha e 13 ha não obtiveram registros de predação de sementes de $S$. romanzoffiana, o que pode indicar baixa densidade de indivíduos ou a extinção dos Sciurus ingrami no local. Fragmentos de pequenos tamanhos são ambientes qualitativamente desfavoráveis para os esquilos por possuírem baixas percentagens de cobertura vegetal devido a área nuclear muito reduzida ou inexistente (Laurance et al., 2000), e os esquilos são dependentes de ambientes com densa vegetação por serem essencialmente arborícolas (Carey et al., 1999).

Os Sciuridae possuem dietas similares, alimentando-se principalmente de sementes duras ("nuts") e fungos (Carey et al., 1999). As espécies com sementes duras são principalmente espécies secundárias, e fragmentos pequenos são compostas basicamente por espécies pioneiras (Gascon et al., 1998). Laurance et al. (2000) verificou que árvores secundárias são vulneráveis à fragmentação devido àalta mortalidade devido ao aumento da ação de ventos 
e densidade de lianas próximas àborda. Fragmentos pequenos possuem maior relação perímetro/superfície, sob intenso efeito do ambiente de borda (Estrada \& Coates-Estrada, 2002; Hill \& Curran, 2001; Turner, 1996), não comportando espécies secundárias nem umidade que propicie o desenvolvimento de fungos, devido à extrapolação do ressecamento característico da borda da mata (Murcia, 1995).

Os fragmentos que obtiveram alta taxa de predação de sementes no microhábitat de clareiras correspondem aos remanescentes que possuem clareiras com pequena abertura de dossel. Bayne \& Hobson (2000) verificaram que apesar de essencialmente arborícolas, somente grandes aberturas de dossel são impermeáveis aos predadores Sciurus ingrami. A predação de sementes de $S$. romanzoffiana ocorreu de forma mais intensa em locais com fácil acesso ঝ̀ sementes, como pontos com lianas lenhosas conectando copa de árvores ao solo onde estavam depositadas as sementes.

Os pequenos roedores não Sciuridae são considerados importantes predadores de sementes (Laurance, 1994; Malcolm, 1994) mas no presente estudo somente em uma estação experimental, situada na borda do fragmento com 33.845 ha, foram encontradas sementes evidentemente predadas por este grupo. As sementes de $S$. romanzoffiana podem possuir o endocarpo muito duro para os pequenos roedores acessarem 0 endosperma, podendo representar muito custo energético muito alto. Do total de sementes localizadas predadas, os pequenos roedores e porcos totalizaram apenas $4 \%$, ao passo que $96 \%$ foram danificadas pelos $S$. ingrami.

Os $S$. ingrami possuem dois períodos reprodutivos ao ano, sendo um no verão e um no inverno (Bordignon \& Monteiro-Filho, 2000). O período reprodutivo dos esquilos durante o inverno coincide com o pico de frutificação S. romanzoffiana. Glanz et al. (1984) observou que Sciurus granatensis agem como principal predador de sementes da palmeira Attalea butyracea no Barro Colorado ( $\mathrm{BCl}$, Panamá), e que a reprodução dos esquilos está limitada e ajustada com a produção de frutos de $A$. butyracea. É possível que em 
Florestas Semidecíduas a frutificação de Syagrus romanzoffiana seja um fator limitante para a reprodução dos esquilos Sciurus ingrami.

Os fragmentos com pequena área possuem baixa densidade de esquilos. Bayne \& Robson (2000) estudando fragmentos de 0,2 a 82 ha, e comparando-os com uma floresta contínua (382.500 ha), verificaram que à medida que aumenta a área de cobertura vegetal a densidade de esquilos também aumenta, e que as áreas de 82 ha possuem maior densidade de esquilos que a floresta contínua. Resultado semelhante foi observado com a taxa de predação de sementes de S.romanzoffiana. Nos menores fragmentos florestais $(9,5$ ha e $13 \mathrm{ha})$ não houve registro de predação de sementes de $S$. romanzoffiana, porém a medida que o tamanho da área aumenta, a taxa de predação de sementes aumenta até o fragmento de 374 ha. Porém na área de 1471 ha o comportamento se inverte, com uma diminuição acentuada na percentagem total de sementes predadas (Figura 3). Esta mudança pode estar relacionada (1) com a existência de um tamanho de área limiar entre 374 ha e 1471 ha, fazendo com que haja uma queda ra curva da taxa de predação, sendo assimétrica para a esquerda, ou (2) com a possibilidade de que se caso tivessem sido avaliados fragmentos com menores intervalos de tamanho inexistente neste ecossistema, a taxa de predação nos fragmentos poderia obter um padrão de distribuição normal. Em ambas possibilidades o aumento na predação estaria relacionado com o fato de que a medida que aumenta a quantidade de recursos e hábitats para os Sciurus sem a presença de seus predadores naturais, estes se tornam mais abundantes ocupando todos os microhábitats, resultando em altas percentagens de predação de sementes nestes fragmentos ( 374 ha). Já nos fragmentos florestais que comportam grandes carnívoros ( $1.471 \mathrm{ha}$ ), os Sciurus são menos abundantes, distribuídos de forma heterogênea ao longo do fragmento, resultando menores percentagens de predação de sementes. 


\subsection{Características da estrutura dos microhábitats}

O gráfico de dispersão dos valores dos autovetores gerados pelo MDS formou três agrupamentos correspondentes aos três microhábitats avaliados: clareira $(A)$, borda $(B)$ e interior de mata $(C)$ - caracterizados pelos fragmentos com área superior a 200 ha (Figura 6). Os microhábitats dos remanescentes Po e $\mathrm{Pe}$, pontos não agrupados, se distinguiram dos demais fragmentos por ambos possuírem dosséis descontínuos, altas freqüências de troncos caídos, de lianas herbácea e lenhosas, e uma baixa percentagem de cobertura de 0 a $0,5 \mathrm{~m}$ por plântulas. A borda da mata do remanescente com 13 ha se distinguiu fortemente dos microhábitats dos demais fragmentos por constituir-se essencialmente por gramíneas e bambus.

Os remanescentes com 13 ha e 9,5 ha não possuem distinção na caracterização dos microhábitats florestais devido à expansão da borda a toda a extensão do fragmento, não diferindo biótica e abioticamente entre borda, interior de mata e clareiras. Pimm (1998), ao estudar as alterações na composição de espécies, na dinâmica de populações e no fluxo de carbono em fragmentos experimentais do Projeto Dinâmica Biológica de Fragmentos Florestais (PDBFF - Amazônia), observou que fragmentos com áreas inferiores a 36 ra são compostos predominantemente por ambiente de borda. $O$ autor encontrou $10 \%$ de perda de biomassa vegetal após 4 anos de isolamento do fragmento devido à alta mortalidade de indivíduos arbóreos. Laurance et al. (2000) encontraram maior abundância de lianas em uma distância de $100 \mathrm{~m}$ da borda da mata, e atribuíram esse aumento a uma das causas do incremento na mortalidade de árvores com grande porte na borda da mata nos fragmentos do PDBFF. Laurance (2002), avaliando o aumento na taxa de mortalidade de espécies arbóreas em remanescentes florestais, verificou uma aceleração na dinâmica das espécies, com $\mathrm{o}$ incremento nas taxas de crescimento e mortalidade quando comparadas com as taxas anteriores ao processo de 
fragmentação. Em fragmentos com pequena área, como 13 ha e 9,5 ha, há altas freqüências de troncos de árvores caídas, de densidades de lianas e de espécies pioneiras, como mamica de porca (Zanthoxyllum spp.), o guaritá (Astronium graveolens), o pau d'alho (Gallesia integrifolia) dentre outras (Rodrigues, 1999), evidências de que as espécies vegetais estejam sofrendo um hiperdinamismo em toda a extensão nestes fragmentos, sendo ambientes desfavoráveis para o estabelecimento de espécies secundárias, como a palmeira S. romanzoffiana.

A borda de mata do fagmento com 33.845 ha apresentou uma maior similaridade com os ambientes de interior de mata dos remanescentes com 13 e 9,5 ha que com o microhábitat de borda de mata dos fragmentos com áreas superiores a 200 ha. Tanto a borda da área com 33.845 ha quanto o interior de mata dos fragmentos com 13 ha e 9,5 ha possuem alta mortalidade de árvores, levando a uma alta freqüência de troncos caídos e baixas percentagens de cobertura de dossel, porém são encontrados alguns indivíduos arbóreos de grande porte. $\mathrm{Na}$ borda do fragmento com 33.845 ha são encontrados alguns indivíduos emergentes como a peroba-rosa (Aspidosperma polyneuron). A presença de árvores de grande porte e a não formação de densos emaranhados de lianas e ramos distinguem a borda do remanescente com 33.845 ha da dos fragmentos com 1.471 ha, 374 ha, 230 ha e 208 ha, fragmentos que constituíram o agrupamento correspondente ao de borda de mata.

A característica que determinou o agrupamento de borda de mata foi a formação de densos emaranhados de lianas e ramos, resultando em altas percentagens de cobertura de zero a $1 \mathrm{~m}$ de altura e baixa cobertura acima de um metro. O desenvolvimento de ramos laterais de árvores na borda da mata pode representar a principal causa da manutenção das características do microhábitat de interior de mata, funcionando como uma barreira para a penetração das condições atmosféricas externas (Mourelle et al., 2001). 
As lianas requerem um maior nível de luminosidade para o seu estabelecimento e sobrevivência, estando associadas com grandes aberturas de dossel, como ocasionadas pela formação de clareiras ou por perturbações (Schnitzer \& Bongers 2002). As lianas atuam em diversos aspectos da dinâmica florestal, suprimindo a regeneração arbórea, aumentando a mortalidade de árvores e unindo fisicamente as árvores, promovendo vias aos animais arborícolas (Schnitzer \& Bongers, 2002).

Apesar de freqüentes em todos microhábitats em todos os fragmentos amostrados, a freqüência e abundância de lianas aumentaram à medida que diminui o tamanho do fragmento. Discordando de Mesquita et al. (1999), onde afirma que o aumento da quantidade de lianas está intimamente associada com uma maior mortalidade de árvores, as maiores freqüências e densidades de lianas estiveram relacionadas com o grau de perturbação: seja por possuírem pequena área, por ação do efeito de borda ou por extração seletiva de madeira, como no caso dos remanescentes pertencentes a Fazenda Barreiro Rico, os com 1.471 ha e 374 ha. Tais evidências corroboram com a hipótese proposta por DeWalt et al. (2000), onde ao compararem como em florestas secundárias (20 - 40 anos) com maduras (idade superior a 70 anos) no Panamá, constataram que os ambientes sob forçantes antropogênicas possuem maior quantidade de lianas.

A baixa cobertura vegetal no intervalo de 0 a $0,5 \mathrm{~m}$ de altura se deu devido ao baixo estabelecimento de plântulas nos menores fragmentos florestais amostrados, os com 13 ha e 9,5 ha. Bruna (1999) avaliando a taxa de germinação de sementes de Heliconia acuminata verificou que a germinação de sementes em florestas contínuas é de 3 a 7 vezes superior que em fragmentos florestais, atribuindo o baixo recrutamento em fragmentos devido æ̀ alterações microclimáticas, aumento na predação de sementes e no acúmulo de liteira em áreas sob efeito de borda, devido à diminuição na decomposição de folhas (Didham, 1998). Elias (1997) testando a influência da fragmentação florestal na sobrevivência de plântulas de Copaifera multijuga transplantadas na 
Amazônia também verificou uma maior taxa ce sobrevivência em fragmentos com maiores áreas.

O agrupamento de interior de mata foi estabelecido por fragmentos com altas percentagens de cobertura acima de meio metro e baixa cobertura de plântulas (0 a 0,5 m), resultando maiores distâncias do ponto central da estação experimental à estrutura com diâmetro superior a $1 \mathrm{~cm}$ para estes intervalos de altura neste microhábitat. A cobertura vegetal nos pontos de interior de mata foi atribuída principalmente pelas coberturas do sub-bosque e do dossel, embora seja freqüente a presença de lianas nesse microhábitat. $O$ agrupamento de interior de mata distinguiu-se da borda por possuir maiores percentagens de cobertura vegetal acima de um metro e menor abaixo desta altura. Apesar de mais abundantes em bordas e clareiras, as lianas são freqüentes no microhábitat de interior de mata, pois uma vez estabelecida as lianas são aptas a sobreviver após a formação de um sub-bosque (Schnitzer \& Bongers, 2002).

As clareiras foram caracterizadas pela alta freqüência de troncos caídos, alta percentagem de cobertura vegetal até meio metro devido a alta densidade de plântulas e de lianas, e baixa cobertura acima de meio metro. Os fragmentos de 2.178 ha, 1.471 ha, 374 ha, 230 ha e 208 ha possuem grande quantidade de pequenas clareiras ao longo do fragmento, ao passo que as do fragmento de 33.845 ha são formadas por quedas de árvores de grande porte, resultando em maiores aberturas de dossel. A alta freqüência de pequenas clareiras nos fragmentos de 2.178 ha, 1.471 ha, 374 ha, 230 ha e 208 ha pode estar relacionada ao hiperdinamismo nestes remanescentes. Laurance (2002) sugere que a fragmentação acelera a dinâmica florestal quando comparada com a de ambientes contínuos, alterando o regime de perturbação, taxas de mortalidade e de recrutamento, flutuações de populações e de indivíduos.

O fator que determinou as maiores taxas de abundância de esquilos e presença de animais de grande porte foi a manutenção das características do microhábitat de interior de mata. Surpreendentemente os fragmentos com 
maiores Sl, isto é, com formas mais irregulares, apresentaram maior diversidade de mamíferos de grande porte. Este fator pode estar associado com (1) a maior diversidade de ambientes em fragmentos com formas mais irregulares, corroborando com a hipótese de Leopold ou (2) com o fato de que os fraghmentos amostrados de maior área possuem formas mais irregulares.

\subsection{A fragmentação florestal e a predação de sementes de Syagrus romanzoffiana}

Com as extinções decorrentes do processo de fragmentação florestal pela perda de hábitat, além da diminuição da riqueza direta de espécies, a organização das comunidades tróficas se modifica (Terborgh et al., 2001). Estas alterações podem levar a distorções ecológicas, como o aumento no número de mamíferos predadores de sementes (Terborgh et al., 2001) após a extinção de grandes carnívoros em fragmentos florestais. $O$ aumento na distribuição destes predadores de sementes pode ter efeitos prejudiciais principalmente para as populações de espécies vegetais que possuem sementes de grande tamanho (Asquith et al., 1997 e Sork, 1987), como Syagrus romanzoffiana, devido à inexistência de locais adequados para o estabelecimento de novos indivíduos ("safe sites"). Manzatto (2001), comparando a estrutura da comunidade arbórea do fragmento florestal de 230 ha de 1998 com de 1978, observou que a população de S. romanzoffiana diminuiu consideravelmente. Os resultados deste estudo demonstram que fragmentos florestais com de pequeno tamanho ( $<1.000$ ha) podem não possuir condições para a manutenção de populações de Syagrus romanzoffiana, seja por forçantes abióticas (<100 ha) ou por baixa sobrevivência de sementes pós dispersas (<1.000 ha).

Neste estudo foram identificados dois fatores que prejudicam a sobrevivência de sementes da palmeira $S$. romanzoffiana pós-dispersas: (1) os 
fatores abióticos presentes em fragmentos com toda extensão sob efeito de borda (13 ha e 9,5 ha); e (2) fatores bióticos, como alta densidade de predadores de sementes em todos microhábitats, como nos fagmentos com 230 ha e 374 ha; sugerindo que para a sua conservação são necessários fragmentos florestais de grandes áreas (>1.000 ha).

Este estudo sugere que em fragmentos pequenos ( $<100 \mathrm{ha})$ seja feito $o$ manejo para o desenvolvimento do sub - bosque e favorecimento no estabelecimento de espécies secundárias, reconstituindo o microhábitat de interior de mata. Com o incremento do sub-bosque há a possibilidade de que com hábitos arborícolas/escansórios ocupem estes ambientes. Tais medidas atenuariam os efeitos abióticos. Nos fragmentos "médios" ( $>100$ ha $\mathrm{e}<1.000$ ha), para assegurar a conservação da palmeira Syagrus romanzoffiana, sugerese que suas sementes pós - dispersas sejam protegidas por gaiolas que impeçam o acesso dos predadores ì sementes, assegurando locais seguros em microhábitat seminaturais e minimizando a pressão biótica. Nestes fragmentos é importante também que seja feito o monitorando a dinâmica das espécies arbóreas, visando a elaboração um plano de gerenciamento adequado para minimizar os efeitos de borda e assegurar a manutenção das características dos microhábitats de interior de mata e clareira.

A maioria dos estudos sobre a fragmentação florestal presente na literatura avalia a resposta de espécies e/ou comunidades à insularização do hábitat. Apesar de importantes, estes trabalhos não consideram os efeitos da fragmentação florestal nos processos ecológicos e de ecossistemas conhecimentos escassos, porém fundamentais para a compreensão dos efeitos decorrentes da fragmentação e que podem possuir grandes implicações para o gerenciamento e conservação dos ecossistemas fragmentados. 


\section{CONCLUSÕES}

1. Fragmentos florestais "pequenos" ( $<100 \mathrm{ha})$ não possuem ambientes florestais, sendo toda a extensão dominada por ambiente de borda de mata.

2. Fragmentos florestais "médios" (entre 100 e 1000 ha) possuem altas percentagens de predação de sementes de Syagrus romanzoffiana, constituindo remanescentes desfavoráveis para a manutenção das populações desta espécie.

3. Os fatores que tornam os fragmentos florestais $<1.000$ ha desfavoráveis para o estabelecimento de sementes de $\mathrm{S}$. romanzoffiana pós - dispersas foram os abióticos para fragmentos pequenos e bióticos para os médios.

4. Não foi observada remoção secundária, sendo todas as sementes removidas localizadas evidentemente predadas.

5. O principal predador de sementes de S. romanzoffiana foi o esquilo caxinguelê (Sciurus ingrami)

6. Os predadores de sementes de $S$. romanzoffiana em fragmentos florestais $<1.000$ ha foram exclusivamente os esquilos ( $S$. ingrami). Nos fragmentos maiores (>1.000 ha) houve predação por outros grupos, como o cateto (Pecari tajacu), o queixada (Tayassu pecari) e pequenos roedores. 
7. Para a conservação da palmeira S. romanzoffiana sem intervenção são necessários fragmentos florestais maiores que 1.000 ha

8. Em fragmentos florestais menores que 100 ha é necessário o manejo para o desenvolvimento do sub - bosque e favorecimento no estabelecimento de espécies secundárias a fim de reconstituir o microhábitat de interior de mata.

9. Nos fragmentos que obtiveram altas percentagens de predação de sementes da palmeira Syagrus romanzoffiana (entre 100 ha 1.000 ha), sugere-se que suas sementes pós - dispersas sejam protegidas por gaiolas, impedindo o acesso dos predadores æ̀ sementes, e desta forma assegurando locais seguros em microhábitat seminaturais e minimizando a pressão biótica. para assegurar a conservação. 


\section{REFERÊNCIAS BIBLIOGRÁFICAS}

AIZEN, M. A.; FEINSINGER, P. Habitat fragmentation, native insect pollinators, and feral honey-bees in Argentine Chaco Serrano. Ecological Applications, v. 4,p. 378-392, 1994.

AIZEN, M. A.; FEINSINGER, P. Forest fragmentation, pollination, and plant reproduction in a chaco dry forest, Argentina. Ecology, v. 75, p. 330-351, 1994.

ASQUITH, N. M.; TERBORGH, J.; ARNOLD, A. E.; RIVEROS, C. M. The fruits the agouti ate: Hymenaea courbaril seed fate when its disperser is absent. Journal of Tropical Ecology, v. 15, p. 229-235, 1999.

ASQUITH, N. M.; WRIGHT, S. J.; CLAUSS, M. J. Does mammal community composition control recruitment in neotropical forests? Evidence from Panama. Ecology, v. 78, p. 941-946, 1997.

ASSUMPÇÃO, C. T., LEITÃO - FILHO. H. F.; CESAR, O. Descrição das matas da Fazenda Barreiro Rico, Estado de São Paulo. Revista Brasileira de Botânica, v. 5, p. 53-66. 1982.

AUSPURGER, C. K. Seed dispersal of the tropical tree, Platypodium elegans, and the escape of its seedlings from fungal pathogens. Journal of Ecology , v. 71, p. 759-771, 1983. 
AUSPURGER, C. K. Seedling survival of tropical tree species: Interactions ofdispersal distance, light-gapsand pathogens. Ecology, v. 65, p. 1075-1712, 1984.

BALDI, A. Microclimate and vegetation edge effects in a reedbed in Hungary. Biodiversity Conservation, v. 8, p. 1697-1706, 1999.

BAYNE, E.; HOBSON, K. Relative use of contiguous and fragmented boreal forest by red squirrels (Tamiasciurus hudsonicus). Canadian Journal of Zoology, v. 78, p. 359-365, 2000.

BENÍTEZ-MALVIDO, J. Impact of forest fragmentation on seedling abundance in a Tropical Rainforest. Conservation Biology, v. 12, p. 380-389, 1998.

BENÍTEZ-MALVIDO, J.; GARCÍA-GUZMÁN, G. Leaffungal incidence and herbivory on tree seedlings in Tropical Rainforest fragments: an experimental study. Biological Conservation, v. 91, p. 143-150, 1999.

BERNARDO, C.S.S. Censo de mamíferos diurnos em um fragmento florestal no sudeste do Brasil. Rio Claro, 2001. Monografia (Bacharelado) - Instituto de Biociências - Universidade Estadual Paulista "Júlio de Mesquita Filho" .

BONADIE, W. A.; BACON, P. R. Year-round utilization of fragmented palm swamp forest by Red-bellied macaws (Ara manilata) and Orange-winged parrots (Amazona amazonica) in the Nariva Swamp (Trinidad). Biological Conservation, v. 95, p. 1-5, 2000.

BORDIGNON, M.; MONTEIRO-FILHO, E. L. A. Behaviour and daily activity of the squirrel Sciurus ingrami in a secondary araucaria forest in southern Brazil. Canadian Journal of Zoology, v. 78, p. 1732-1739, 2000. 
BORDIGNON, M.; MARGARIDO, T. C. C.; LANGE, R. R. Formas de abertura dos frutos de Syagrus romanzoffiana (Chamisso) Glassman efetuadas por Sciurus ingrami Thomas (Rodentia, Sciuridae). Revista Brasileira de Zoologia , v. 13, p. 821-828, 1996.

BOWERS, M. A.; DOOLEY JR., J. L. Predation hazard and seed removal by small mammals: microhabitat versus patch scale effects. Oecologia, v. 94, p. 247-254, 1993.

BRAND, L. A.; GEORGE, T. L. Predation risks for nesting birds in fragmented coast redwood forest. Journal of Wildlife Management, v. 64, p. 42-51, 2000.

BRIANI, D.C.; SANTORI, R.T.; VIEIRA, M.V.; GOBBI, N. Mamíferos nãovoadores de um fragmento de mata mesófila semidecídua do interior do Estado de São Paulo, Brasil. Holos Environment, v. 1, p. 141- 149, 2001.

BROOKS, T. Conservation biology: living on the edge. Nature, v. 403, p. 26-29, 2000.

BROTHERS, T.S.; SPINGARN, A. Forest fragmentation and alien plant invasion of Central Indiana old-growth forests. Conservation Biology, v. 6, p. 91-100, 1992.

BROWN, J. H.; HESKE, E. J. Control of a desert-grassland transition by a keystone rodent guild. Science, v. 250, p. 1705-1707, 1990

BROWN, J. H.; BROWN JR., K. S. Habitat alteration and species loss in Brazilian forest. In: WHITMORE, T. C.; SAYER, J. A. (Ed.). Tropical deforestation and species extinction. London: Chapman and Hall Books, 1992. p. 119-142. 
BROWN JR., K. S.; HUTCHINGS, R. W. Distubance, fragmentation, and the dynamics of diversity in amazonian forest butterflies. In: LAURANCE, W.F.; BIERREGAARD JR., R.O. (Ed.). Tropical forest remnants: ecology, management, and conservation of fragmented communities. Chicago: The University of Chicago Press, 1997. p 91-110.

BRUNA, E. M. Seed germination in rainforest fragments. Nature, v. 402, p. 139, 1999

BURKEY, T. V. Edge effects in seed and egg predation at two Neotropical Rainforest sites. Biological Conservation, v. 66, p. 139-143, 1993

CADENASSO, M. L.; PICKETT, S. T. A. Linking forest edge stucture to edge function: mediation of herbivore damage. Journal of Ecology, v. 14, p. 31 44, 2000.

CAMARGO, J. L. C.; KAPOS, V. Complex edge effects on soil-moisture and microclimate in Central Amazonian Forest. Journal of Tropical Ecology, v. 11, p. 205-221, 1995

CARDOSO, S. R. S.; ELOY, N. B.; PROVAN, J.; CARDOSO, M. A.; FERREIRA, P. C. G. Genetic differentiation of Euterpe edulis Mart. populations estimated by AFLP ana lysis. Molecular Ecology, v. 9, p. 1753-1760, 2000

CAREY, A. B.; KERSHNER, J.; BISWELL, B.; DE TOLEDO, L. D. Ecological scale and forest development: squirrels, dietary fungi, and vascular plants in managed and unmanaged forests. Wildlife Monographs, v. 142, p. 5-71, 1999.

CARVALHO, K. S.; VASCONCELOS, H. L. Forest fragmentation in Central Amazonia and its effects on litter-dwelling ants. Biological Conservation, v. 91 , p. 151-157, 1999. 
CARVALHO, R. M.; MARTINS, F. R.; SANTOS, F. A. M. Leaf ecology of prereproductive ontogenetic stages of the palm tree Euterpe edulis Mart. (Arecaceae). Annals of Botany, v. 83, p. 225-233, 1999

CASGRAIN, P.; LEGENDRE, P. The R Package for multivariate ans spatial analysis - version 4.0 (development release 6): user's manual. http://www.fas.umontreal.ca/BIOL/Casgrain/en/labo/. (02 jun. 2002).

CATHARINO, E. L. M. Estudos fisionômicos-florísticos e fitossociológicos em matas residuais secundárias no Município de Piracicaba, SP. Campinas, 1989. Dissertação (Mestrado) -Instituto de Biociências, Universidade Estadual de Campinas.

CESAR, O.; LEITÃO FILHO, H. F. Estudo florístico quantitativo de mata mesófila semidecídua na Fazenda Barreiro Rico, Município de Anhembi, S. P. Revista Brasileira de Biologia, v. 50, p. 133-147, 1990.

CHANNELL, R.; LOMOLINO, M. V. Dynamic biogeography and conservation of endangered species. Nature, v. 403, p. 84-86, 2000.

CHEN, F. An empirical model for predicting diurnal air-temperature gradients from edge into old-growth Douglas-fir forest. Ecological Modelling, v. 67, p. $179-198,1993 a$.

CHEN, F. Contrasting microclimates among clearcut edge and interior of old growth Douglas-fir forest. Agricultural and Forest Meteorology, v. 63, p. 219-237, 1993b.

CHIARELLO, A. G. Effects of fragmentation of the Atlantic Forest on mammal communities in south-eastern Brazil. Biological Conservation, v. 89, p. 7182, 1999. 
CINTRA, R Sobrevivência pós-dispersão de sementes e plântulas de três espécies de palmeiras em relação a presença de componentes da complexidade estrutural da Floresta Amazônica. In: GASCON, C., MOUTINHO, P. (Ed.). Floresta Amazônica: dinâmica, regeneração e manejo. Manaus: Instituto Nacional de Pesquisa da Amazônia, 1998. p. 8398.

CINTRA, R. Leaf litter effects on seed and seedling predation of the palm Astrocaryum murumuru and the legume tree Dipteryx micrantha in Amazonian forest. Journal of Tropical Ecology, v. 13, p. 709-725, 1997.

CINTRA, R.; HORNA, V. Seed and seedling survival of the palm Astrocaryum murumuru and the legume tree Dipteryx micrantha in gaps in Amazonian forest. Journal of Tropical Ecology, v. 13, p. 257-277, 1997.

COLLINGE, S. K. Ecological consequences of habitat fragmentation: implications for landscape architecture and planning. Landscape and Urban Planning, v. 36, p. 59-77, 1996.

CONSERVATION-INTERNATIONAL Avaliação e ações prioritárias para a conservação da biodiversidade da Mata Atlântica e Campos Sulinos. Brasília: Ministério do Meio Ambiente, 2000.

COPPLESTONE, D.; JOHNSON, M. S.; JONES, S. R. Radionucleotide behaviour and transport in a coniferous woodland ecosystem: the distribution of radionucleotides in soil and leaf litter. Water Air and Soil Pollution, v. 122 , p. $389-404,2000$. 
CORLETT, R. T.; TURNER, I. M. Long-term survival in tropical forest remnants in Singapore and Hong Kong. In: LAURANCE, W. F., BIERREGAARD JR., R.O. (Ed.). Tropical forest remnants: ecology, management, and conservation of fragmented communities. Chicago: The Chicago University Press, 1997. p 333-345.

CÜLLEN JR., L. Hunting and biodiversity in Atlantic forest fragments, São Paulo, Brazil. Gainesville, 1997. Thesis (M.Sc) - University of Florida.

CÜLLEN JR., L; BODMER, R. E.; VALLADARES-PÁDUA, C. Caça e biodiversidade nos fragmentos florestais da Mata Atlântica, São Paulo, Brasil. In: FANG, T. G.; MONTENEGRO, O. L.; BODMER, R. E. (Ed.). Manejo y conservación de fauna silvestre en América Latina. 1999. p 125-140.

CÜLLEN JR., L.; BODMER, E. R.; VALLADARES-PÁDUA, C. Ecological consequences of hunting in Atlantic forest patches, São Paulo, Brazil. Oryx, v. 35, p. 137-144, 2001.

DANIELSON, W. R.; DEGRAAF, R. M.; FULLER, T. K. Rural and suburban forest edges: effect on egg predators and nest predation rates. Landscape and Urban Planning, v. 38, p. 25-36, 1997.

DENSLOW, J. S. Tropical rain-forest gaps and tree species-diversity. Annual Review of Ecology and Systematics, v. 18, p. 431-451, 1987.

DEWALT, S. J.; SCHNITZER, S. A.; DENSLOW, J. S. Density and diversity of lianas along a chronosequence in a central Panamanian lowland forest. Journal of Tropical Ecology, v. 16, p. 1-19, 2000.

DIDHAM, R. K. Altered leaf-litter decomposition rates in tropical forest fragments. Oecologia, v. 116, p. 397-406, 1998. 
DIRZO, R.; MIRANDA, A. Contemporary neotropical defaunation and forest structure, function, and diversity - A sequel to John Terborgh. Biological Conservation, v. 4, p. 444-447, 1990

DOAK, D. F.; MARINO, P. C.; KAREIVA, P. Spatial scale mediates the influence of habitat fragmentation on dispersal success: implications for conservation. Theoretical Population Biology, v. 41, p. 315-336, 1992.

DUNCAN, R. S.; WENNY, D. G.; SPITZER, M. D.; WHELAN, C. J. Does human scent bias seed removal studies? Ecology, v. 83, p. 2630-2636, 2002.

ELIAS, M. E. A. The influence of fragmentation and survival of seedlings of Copaifera multijuga. Manaus, 1997. Dissertação (Mestrado) - Instituto Nacional de Pesquisas da Amazônia.

EMMONS, L. H. Ecology of Proechimys (Rodentia, Echimyidae) in southeastern Peru. Tropical Ecology, v. 23, p. 290-290, 1982.

EMMONS, L. H.; GENTRY, A. H. Tropical forest structure and the distribution of gliding and prehensile-tailed vertebrates. The American Naturalist, v. 34, p. 513-524, 1983.

ESTRADA, A.; COATES-ESTRADA, R. Bats in continuous forest, forest fragments and in an agricultural mosaic habitat-island at Los Tuxtlas, Mexico. Biological Conservation, v. 103, p. 237-245, 2002.

FACURE, K. G.; GIARETTA, A. A. Food habits of carnivores in a coastal Atlantic forest of southeastern Brazil. Mammalia, v. 60, p. 499-502, 1996.

FERREIRA, L. V.; LAURANCE, W. F. Effects of forest fragmentation on mortality and damage of selected trees in Central Amazonia. Conservation Biology, v. 11, p. 797-801, 1997. 
FLEURY, M.; GALETTI, M. Effects of microhabitat on palm seed predation in two forest fragments in south-east Brazil. Acta Oecologica, 2003. /No prelo/.

FONSECA, G. A. B; ROBINSON, J. G. Forest size and structure: competitive and predatory effects on small mammal communities. Biological Conservation, v. 53, p. 265-294, 1990.

FORGET, P. M. Removal of seeds of Carapa procera (Meliaceae) by rodents and their fate in rainforest in French Guiana. Journal of Tropical Ecology, v. 12 , p. $751-761,1996$.

FORGET, P. M. Effect of microhabitat on seed fate and seedling performance in two rodent - dispersed tree species in rain forest in French Guiana. Journal of Ecology, v. 85, p. 693-703, 1997.

FORGET, P. M.; MILLERON, T. Evidence for secondary seed dispersal by rodents in Panama. Oecologia, v. 87, p. 596-599, 1991.

GALETTI, M.; ALEIXO, A. Effects of palm heart harvesting on avian frugivores in the Atlantic rain forest of Brazil. Journal of Applied Ecology, v. 35, p. 286-293, 1998.

GALETTI, M.; FERNANDEZ, J. C. Palm heart harvesting in the Brazilian Atlantic forest: changes in industry structure and the illegal trade. Journal of Applied Ecology, v. 35, p. 294-301, 1998

GALETTI, M; PASCHOAL, M; PEDRONI, F. Predation on palm nuts (Syagrus romanzo ffiana) by squirrels (Sciurus ingrami) in South-east Brazil. Journal of Tropical Ecology, v. 8, p. 121-123, 1992.

GALETTI, M.; ZIPPARRO, V.; MORELLATO, L. P. Fruit phenology and frugivory on the palm Euterpe edulis in a lowland Atlantic forest of Brazil. Ecotropica, v. 5, p. 115-122, 1999. 
GALETTI, M.; KEUROGHLIAN, A.; HANADA, L.; MORATO, I. Frugivory and seed dispersal by the lowland tapir (Tapirus terrestris) in southeast Brazil. Biotropica, v. 33, p. 723-726, 2001.

GASCON, C.; LOVEJOY, T. E. Ecological impacts of forest fragmentation in central Amazonia. Zoology, Analysis of Complex Systems, v. 101, p. 273280, 1998.

GASPAR, A. Ecologia e comportamento do bugio ruivo, Alouatta fusca (Geoffroy, 1812, Primates: Cebidae), em fragmento de mata de Campinas, SP. Rio Claro, 1997. Dissertação (Mestrado) - Instituto de Biociências, Universidade Estadual Paulista “Júlio de Mesquita Filho".

GHELER-COSTA, C. Mamíferos não voadores do campus "Luiz de Queiroz", da Universidade de São Paulo, em Piracicaba, Estado de São Paulo. Piracicaba, 2002. P.74. Dissertação (Mestrado) - Escola Superior de Agricultura "Luiz de Queiroz", Universidade de São Paulo.

GLANZ, W. E. Food and habitat use by 2 sympatric Sciurus species in central Panama. Journal of mammalogy, v. 65, p. 342-347, 1984.

GOOSEM, M. Effects of tropical rainforest roads on small mammals: edge changes in community composition. Wildlife Research, v. 27, p. 151-163, 2000.

GUIX, J. C.; RUIZ, X.; JOVER, L. Resource partitioning and interspecific competition among coexisting species of guans and toucans in SE Brazil. Netherlands Journal of Zoology, v. 51, p. 285-297, 2001.

HENDERSON, A.; GALEANO, G.; BERNAL, R. Field guide to the palms of the Americas. Princeton: Princeton University Press, 1995. 376 p. 
HEYWOOD, V. H.; MACE, G. M.; MAY, R. M.; STUART, S. N. Uncertainties in extinction rates. Nature, v. 368, p. 105, 1994.

HILL, J. L.; CURRAN, P. J. Species composition in fragmented forests: conservation implications of changing forest area. Applied Geography, v. 21 , p. 157-174, 2001.

HONNAY, O.; VERHEYEN, K.; HERMY, M. Permeability of ancient forest edges for weed plant species invasion. Forest Ecology and Management, v. 161, p. $109-122,2002$.

HULME, P. E. Post-dispersal seed predation in grassland: its magnitude and sources of variation. Journal of Ecology, v. 82, p. 645-652, 1994.

HURLBERT, S. H. Pseudoreplication and the design of ecological field experiments. Ecological Monographs, v. 54, p. 187-211, 1984.

JANZEN, D. H. Seeds in tapir dung in Santa Rosa National Park, Costa Rica. Brenesia, v. 19/20, p. 129-135, 1982.

JANZEN, D. H. The eternal external threat. In: SOULÉ, M. E. (Ed) Conservation biology: the science of scarcity and diversity. Sunderland: Sinauer Associates, 1986. p 286-303.

JANZEN, D. H. Management of habitat fragments in tropical dry forest: growth. Annals of the Missouri Botanical Garden, v. 75, p. 105-116, 1988.

JANZEN, D. H.; MARTIN, P. S. Neotropical anachronism: the fruits the gomphotheres ate. Science, v. 215, p. $19-27,1982$.

JOLY, C. A.; LEITÃO FILHO, H. F.; SILVA, S. M. O patrimônio florístico. In: MARA I. B. C. (Ed.). Mata Atlântica. Rio de Janeiro: Fundação SOS Mata Atlântica, 1991. p $95-125$. 
JOSE, S.; GILLESPIE, A. R.; GEORGE, S. J.; KUMAR, B. M. Vegetation responses along edge-to-interior gradients in a high altitude tropical forest in peninsular India. Forest Ecology and Management, v. 89, p. 51-62, 1996.

KAPOS, V. Effects of isolation on the water status of forest patches in the Brazilian Amazon. Journal of Tropical Ecology, v. 5, p. 173-185, 1989.

KAPOS, V.; WANDELLI, E.; CAMARGO, J. L. C.; GANADE, G. M. S. Edgerelated changes in environment and plant responses due to forest fragmentation in central Amazonia. In: LAURANCE, W. F.; BIERREGAARD JR., R. O. (Ed.). Tropical forest remnants: ecology, management, and conservation of fragmented communities. Chicago: The University of Chicago Press, 1997. p. 33-44.

KING, D. I.; DEGRAAF, R. M. The effect of forest roads on the reproductive success of forest-dwelling passerine birds. Forest Science, v. 48, p. 391396, 2002.

LAURANCE, W. F. Edge effects in tropical forest fragments: application of a model for the design of nature reserves. Biological Conservation, v. 57, p. 205-219, 1991.

LAURANCE, W. F. Rainforest fragmentation and the structure of a small mammal communities in tropical Queensland. Biological Conservation, v. 69, p. $23-32,1994$.

LAURANCE, W. F. Hyper-disturbed parks: edge effects and the ecology of isolated rainforest reserves in tropical Australia. In: LAURANCE, W. F.; BIERREGAARD JR., R. O. (Ed.). Tropical forest remnants: ecology, management, and conservation of fragmented communities. Chicago: The University of Chicago Press, 1997. p. 71-83. 
LAURANCE, W. F. Reflections on the tropical deforestation crisis. Biological Conservation, v. 91, p. 23-32, 1999.

LAURANCE, W. F. Hyperdinamism in fragmented habitats. Journal of Vegetation Science, v. 13, p. 595-602, 2002.

LAURANCE, W. F.; BIERREGAARD JR., R. O. (Ed.). Tropical forest remnants: ecology, management, and conservation of fragmented communities. Chicago: The University of Chicago Press, 1997. 504 p.

LAURANCE, W. F.; YENSEN, E. Predicting the impacts of edge effects in fragmented habitats. Biological Conservation, p. 55, p. 77-92, 1991.

LAURANCE, W. F.; FERREIRA, L. V.; RANKIN-DE MERONA, J. M.; LAURANCE, S. G. Rainforest fragmentation and the dynamics of amazonian tree communities. Ecology, v. 79, p. 2032-2040, 1998.

LAURANCE, W. F.; DELAMONICA, P.; LAURANCE, S. G.; VASCONCELOS, $\mathrm{H}$. L.; LOVEJOY, T. E. Rainforest fragmentation kills big trees. Nature, v. 404, p. 836, 2000.

LAURANCE, W. F.; LOVEJOY, T. E.; VASCONCELOS, H. L.; BRUNA, E. M.; DIDHAM, R. K.; STOUFFER, P. C.; GASCON, C.; BIERREGAARD JR., R. O.; LAURANCE, S. G.; SAMPAIO, E. Ecosystem decay of Amazonian forest fragments: a 22-year investigation. Conservation Biology, v. 16, p. 605 618, 2002. 
LAURANCE, W. F.; BIERREGAARD JR., R. O.; GASCON, C.; DIDHAM, R. K.; SMITH, A. P.; LYNAM, A. J.; VIANA, V. M.; LOVEJOY, T. E.; SIEVING, K. E.; SITES, J. W.; ANDERSEN, M.; TOCHER, M. D.; KRAMER, E. A.; RESTREPO, C.; MORITZ, C. Tropical forest fragmentation: synthesis of a diverse and dynamic discipline. In: LAURANCE, W. F.; BIERREGAARD JR., R. O. (Ed.). Tropical forest remnants: ecology, management, and conservation of fragmented communities. Chicago: The University of Chicago Press, 1997. p. 502-514.

LEGENDRE, P.; LEGENDRE, L. Numerical ecology. Amsterdam: Elsevier Science, 1998. $853 \mathrm{p}$.

LEITÃO FILHO, H. F. Ecologia da Mata Atlântica em Cubatão. Campinas: Editora Unesp; Unicamp, 1993.

LONGLAND, W. S.; PRICE, M. V. Direct observations of owls and heteromid rodents: can predation risk explain microhabitat use? Ecology, v. 72, p. 2261-2273, 1991.

LORENZI, H., DE SOUZA, H. M., MEDEIROS-COSTA, J. T., DE CERQUEIRA, L. S. C., VON BEHR, N. Palmeiras do Brasil: exóticas e nativas. Nova Odessa: Editora Plantarum, 1996. 320 p.

LOVEJOY, T. E. Foreword. In: LAURANCE, W. F.; BIERREGAARD JR., R. O. (Ed.). Tropical forest remnants: ecology, management, and conservation of fragmented communities. Chicago: The University of Chicago Press, 1997. p.ix. 
LOVEJOY, T. E.; BIERREGAARD JR., R. O.; RYLANDS, A. B.; MALCOLM, J. R.; QUINTELA, C. E.; HARPER, L. H.; BROWN JR., K. S.; POWELL, A. H.; POWELL, G. V. N.; SCHUBART, H. O. R.; HAYS, M. B. Edge and other effects if isolation on Amazon Forests fragments. In: SOULÉ, M. E. (Ed.). Conservation biology: the science of scarcity and diversity. Sunderland: Sinauer Associates, 1986. p 257-285.

LURZ, P. W. W.; GARSON, P. J.; WAUTERS, L. A. Effects of temporal and spatial variation in habitat quality on red squirrel dispersal behaviour. Animal Behaviour, v. 54, p. 427-435, 1997.

LYNAM, A. J.; BILLICK, I. Differencial responses of small mammals to fragmentation in a Thailand tropical forest. Biological Conservation, v. 91, p. 191-200, 1999.

MACARTHUR, R. H.; WILSON, E. O. The theory of island biogeography. Pincenton: Princenton Univeersity Press, 1967, 224 p.

MAGALHÃES, J. C. R. As aves da Fazenda Barreiro Rico. São Paulo: Editora Plêiade, 1999.

MALCOLM, J. R. Edge effects in Central Amazonian forest fragments. Ecology, v. 75, p. 2438-2445, 1994.

MANZATTO, A. G. Dinâmica de um fragmento de Floresta Estaciional Semidecidual do Municipio de Rio Claro - S.P. Diversidade, riqueza florística e estrutura da comunidade no período de 20 anos (1978-1998). Rio Claro, 2001. 127p. Dissertação (Mestrado) - Instituto de Biociências, Universidade Estadual Paulista "Júlio de Mesquita Filho". 
MARTINS, M.M. Estratégias alimentares e dispersão de sementes por Alouatta guariba e Brachyteles arachnoides em um fragmento de floresta semidecídua. São Paulo, 2003. Tese (Doutorado) - Instituto de Biociências, Universidade de São Paulo.

MATLACK, G. R. Vegetation dynamics of the forest edge - trends in space and successional time. Journal of Ecology, v. 82, p. 113-123, 1994.

MATOS, D. M. S.; WATKINSON, A. R. The fecundity, seed, and seedling ecology of the edible palm Euterpe edulis in southeastern Brazil. Biotropica, v. 30, p. 595-603, 1998.

MATOS, D. M. S.; FRECKLETON, R. P.; WATKINSON, A. R. The role of density dependence in the population dynamics of a tropical palm. Ecology, v. 80, p. 2635-2650, 1999.

MCALPINE, C. A.; FENSHAM, R. J.; TEMPLE-SMITH, D. E. Biodiversity conservation and vegetation clearing in Queensland: principles and thresholds. Rangeland Journal, v. 24, p. $36-55,2002$

MCCOLLIN, D. Forest edges and habitat selection in birds: a functional approach. Ecography, v. 21, p. 247-260, 1998.

MESQUITA, R. C. G.; DELAMONICA, P.; LAURANCE, W. F. Effect of surrounding vegetation on edge-related tree mortality in Amazonian forest fragments. Biological Conservation, v. 91, p. 129-134, 1999.

METZGER, J. P. Tree functional group richness and landscape structure in a Brazilian tropical fragmented landscape. Ecological Applications, v. 10, p. 1147-1161, 2000. 
MORUZZI, T. L.; FULLER, T. K.; DEGRAAF, R. M.; BROOKS, R. T.; LI, W. J. Assessing remotely triggered cameras for surveying carnivore distribution. Wildlife Society Bulletin, v. 30, p. 380-386, 2002.

MOURELLE, C.; KELLMAN, M.; KNOW, L. Light occlusion at forest edges: an analysis of tree architectural characteristics. Forest Ecology and Management, v. 154, p. 179-192, 2001.

MURCIA, C. Edge effects in fragmented forests: implications for conservation. Trends in Ecology \& Evolution, v. 10, p. 58-62, 1995.

MYERS, N. Protected areas - protected from a greater what. Biodiverstity and Conservation, v. 3, p. 411-418, 1994.

MYERS, N.; MITTERMEIER, R. A.; MITTERMEIER, C. G.; FONSECA, G. A. B.; KENT, J. Biodiversity hotspots for conservation priorities. Nature, v. 403, p. $853-858,2000$.

MYSTER, R. W.; PICKETT, S. T. A. Effects of litter, distance, density and vegetation patch type on postdispersal tree seed predation in old fields. Oikos, v. 66, p. 381-388, 1993.

NASCIMENTO, H. E. M. Estrutura e dinâmica de um fragmento de floresta Estacional Semidecidual na Região de Piracicaba, SP. Piracicaba, 1998. Dissertação (Mestrado) - Escola Superior de Agricultura "Luiz de Queiroz", Universidade de São Paulo.

OLMOS, F.; PARDINI, R.; BOULHOSA, R. L. P.; BURGI, R.; MORSELLO, C. Do tapirs steal food from palm seed predators or give them a lift? Biotropica, v. 31, p. 375-379, 1999. 
OLMOS, F; GLAND, S. Tapirs as seed dispersers and predators. In: BROOKS, D. M.; BODMER, R. E.; MATOLA, S. (Ed.). Tapirs: status survey and conservation action plan. Gland: IUCN/SSC Tapir Specialist Group, 1997. p 3-9.

OSUNKOYA, O. O. Post dispersal survivorship of north Queensland and rainforest seeds and fruits - effects of forest, habitat and species. Australian Journal of Ecology, v. 19, p. 52-64, 1994.

PAGANO, S. N. Composição florística do extrato arbóreo de uma mata mesófila semidecídua no Município de Rio Claro, SP. Revista Brasileira de Botânica, v. 10, p. 37-47, 1987

PASCHOAL, M.; GALETTI, M. Seasonal food use by the neotropical squirrel Sciurus ingrami in the southeastern. Biotropica, v. 27, p. 268-273, 1995.

PASSOS, F. C. Padrão de atividades, dieta e uso do espaço em um grupo de mico-leão-preto (Leontopithecus chrysopygus) na Estação Ecológica dos Caetetus, S. P. São Carlos, 1998. Tese (Doutorado) - Instituto de Biociências, Universidade Federal de São Carlos.

PATON, P. W. C. The effect of edge on avian nest success - how strong is the evidence. Conservation Biology, v. 8, p. 16-26, 1994.

PATTON, D. R. A diversity index for quantifying habitat edge. Wildlife Society Bulletin, v. 3, p. 171-173, 1975.

PEÑA-CLAROS, M., DEBOO $\mathrm{H}$. The effect of forest successional stage on seed removal of tropical rainforest tree species. Journal of Tropical Ecology, v. 18, p. 261-274, 2002. 
PERES, C. A. Composition, density, and fruiting phenology of arborescent palms in an Amazonian terra-firme forest. Biotropica, v. 26, p. 285-294, 1994.

PERES, C. A. Effects of subsistence hunting on vertebrate community structure in Amazonian forests. Conservation Biology,v. 14:240-253, 2000.

PIMM, S. L. The forest fragment classic. Nature, v. 393, p. 23-24, 1998.

QUINTELA, C. E. An S. O. S. Brazil's beleaguered Atlantic forest. Nature Conservancy Magazine, v. 40, p. 14-19, 1990.

RANTA, P.; BLOM, T.; NIEMELA, J.; JOENSUU, E.; SIITONEN, M. The fragmented Atlantic rain forest of Brazil: size, shape and distribution of forest fragments. Biodiversity and Conservation, v. 7, p. 385-403, 1998.

REDFORD, K. H. The empty forest. BioScience, v. 42, p. 412 - 422, 1992.

REIS, M. S.; FANTINI, A. C.; NODARI, R. O.; REIS, A.; GUERRA, M. P.; MANTOVANI, A. Management and conservation of natural populations in Atlantic rain forest: The case study of palm heart (Euterpe edulis Martius). Biotropica, v. 32, p. 894-902, 2000

RESTREPO, C.; GOMEZ, N. Responses of understory birds to anthropogenic edges in a Neotropical montane forest. Ecological Applications, v. 8, p. 170-183, 1998.

RESTREPO, C.; VARGAS, A. Seeds and seedlings of two neotropical montane understory shrubs respond differently to anthropogenic edges and treefall gaps. Oecologia, v. 119, p. 419-426, 1999.

RESTREPO, C.; GOMEZ, N.; HEREDIA, S. Anthropogenic edges, treefall gaps, and fruitfrugivore interactions in a neotropical montane forest. Ecology, v. 80, p. $668-685,1999$. 
RODEWALD, A. D. Nest predation in forested regions: landscape and edge effects. Journal of Wildlife Management, v. 66, p. 634-640, 2002.

RODRIGUES, R. R. A vegetação de Piracicaba e Municípios do entorno. Circular técnica IPEF, v. 189, p. 1-17, 1999.

RUSSELL, S. K.; SCHUPP, E. W. Effects of microhabitat patchiness on patters of seed dispersal and seed predation of Cercocarpus lidifolius (Rosaceae). Oikos, v. 81, p. 434-443, 1998.

SANCHEZ-CORDERO, V.; MARTÍNEZ-GALLARDO, R. Postdispersal fruit and seed removal by forest understory and in treefall gaps. Oikos, v. 51, p. 71 78, 1998.

SANTOS, T.; TELLERÍA, J. L. Influence of forest fragmentation on seed consumption and dispersal of Spanish juniper Juniperus thurifera. Biological Conservation, v. 70, p. 129-134, 1994.

SANTOS, T.; TELLERÍA, J. L.; VIRGÓS, E. Dispersal of Spanish juniper Juniperus thurifera by birds and mammals in a fragmented landscape. Ecography, v. 22, p. 193-204, 1999

SAS INSTITUTE SAS user's guide: statistics; release 6.03. Cary, 1990.

SAS INSTITUTE JMP: introductory guide - Version 5. Cary, 2002.

SAUNDERS, D. A.; HOBBS, R. J.; MARGULES, C. R. Biological consequences of ecosystem fragmentation: a rewiew. Conservation Biology, v. 5, p. 12 32, 1991.

SCARIOT, A. Seed dispersal and predation of the palm Acrocomi aculeata. Principes, v. 42, p. 5-8, 1998. 
SCARIOT, A. Forest fragmentation effects on palm diversity in central Amazonia. Journal of Ecology,v. 87, p. 66-76, 1999.

SCHLITTER, F. H. M.; MARINES, G.; CESAR, O. Estudos fitossociológicos na floresta do Morro do Diabo (Pontal do Paranapanema, SP). Arquivo de Biologia e Tecnologia, v. 31, p. 217-234, 1995.

SCHNITZER, S. A.; BONGERS, F. The ecology of lianas and their role in forests. Trends in Ecology \& Evolution, v. 17, p. 223-230, 2002.

SCHUPP, E. W. Factors affecting post-dispersal seed survival in a tropical forest. Oecologia, v. 76, p. 525-530, 1988a.

SCHUPP, E. W. Seed and early seedling predation in the forest understory and in treefall gaps. Oikos, v. 51, p. 71-78, 1988b.

SCHUPP, E. W. Arrival and survival in a tropical treefall gaps. Oikos, v. 51, p. $71-78,1988 \mathrm{c}$.

SCHUPP, E. W. Annual variation in seed fall, post-dispersal predation, and recruitment of a neotropical tree. Ecology, v. 71, p. 504-515, 1990.

SCHUPP, E. W. Quantity, quality and the effectiveness of seed dispersal by animals. Vegetatio, v. 108, p. 15-29,1993.

SCHUPP, E. W.; FROST, E. J. Differential predation of Welfia georgii seeds in treefall gaps and the forest understory. Biotropica, v. 21, p. 200-203, 1989.

SCHUPP, E. W.; FUENTES, M. Spatial patterns of seed dispersal and the unification of plant population ecology. Ecoscience, v. 2, p. 267-275, 1995.

SCHUPP, E. W; HOWE, H. F.; AUSPURGER, C. K.; LEVEY, D. J. Arrival and survival in tropical treefall gaps. Ecology, v. 70, p. 562-564, 1989. 
SICK, H. Ornitologia brasileira. Rio de Janeiro: Editora Nova Fronteira, 1997.

SILVA, J. M. C.; TABARELLI, M. Tree species impoverishment and the future flora of the Atlantic forest of northeast Brazil. Nature, v. 404, p. 72-74, 2000.

SIZER, N.; TANNER, E. V. J. Responses of woody plant seedlings to edge formation in a lowland tropical rainforest, Amazonia. Biological Conservation, v. 91, p. 135 - 142, 1999.

SMYTHE, N. Seed survival in the palm Astrocaryum standleyanum: evidence for dependence upon its seed dispersers. Biotropica, v. 21, p. 50 - 56, 1989.

SMYTHE, N. The eternal threat. In: SOULÉ, M. E. (Ed.). Conservation biology: the science of scarcity and diversity. Sunderland: Sinauer Associates, 1986. p 286-303.

SORK, V. L. (1987) Effects of predation and light on seedling establishment in Gustavia superba. Ecology, v. 68, p. 1341-1350, 1987.

SOS MATA ATLÂNTICA. Atlas da evolução dos remanescentes florestais e ecossistemas associados do domínio da Mata Atlântica no período de 1985-1990. São José dos Campos:Fundação SOS Mata Atlântica; Instituto Nacional de Pesquisas Espaciais, 1992.

SOS MATA ATLÂNTICA. Evolução dos remanescentes florestais e ecossistemas associados do domínio da Mata Atlântica. Sào José dos Campos: Fundação SOS Mata Atlântica; Instituto Nacional de Pesquisas Espaciais, 1993.

STEFFAN-DEWENTER, I.; MUNZENBERG, U.; BURGER, C.; THIES, C.; TSCHARMTKE, T. Scale-dependent effects of landscape context on three pollinator guilds. Ecology, v. 83, p. 1421-1432, 2002. 
STEVENS, S. M.; HUSBAND, T. P. The influence of edge on small mammals: evidence from Brazilian Atlantic forest fragments. Biological Conservation, v. 85, p. $1-8,1998$.

TABANEZ, A. A. J.; VIANA, V. M.; DIAS, A. S. Conseqüências da fragmentação e do efeito de borda sobre a estrutura, diversidade e sustentabilidade de um fragmento de floresta de planalto. Revista Brasileira de Biologia, v. 57, p. 47-60, 1997.

TABARELLI, M.; MANTOVANI, W.; PERES, C. A. Effects of habitat fragmentation on plant guild structure in the montane Atlantic forest of southeastern Brazil. Biological Conservation, v. 91, p. 119-127, 1999.

TELLERÍA, J. L.; SANTOS, T. Fragmentación de hábitats florestales y sus consecuencias. In: RODRIGUEZ, R. Z.; IRAOLA, F. I. P. (Ed.). Ecosistemas mediterráneos: análisis funcional. Madrid: Colección Textos Universitarios, 2001.

TELLERÍA, J. L.; SANTOS, T.; ALCÁNTARA, M. Abundance and doodsearching intensity of wood mice (Apodemus sylvaticus) in fragmented forests. Journal of Mammalogy, v. 72, p. 183-187, 1991.

TERBORGH, J. Community aspects of frugivory in tropical forest. In: ESTRADA, A.; FLEMING, T. H. (Ed.). Frugivores and seed dispersal. Wageningen: Dr. W. Junk, 1986a. p 371-384.

TERBORGH, J. Keystone plant resources in the tropical forest. In: SOULÉ, M. E. (Ed.). Conservation biology: the science of scarcity and diversity. Sunderland: Sinauer Associates, 1986b. p. 330-334.

TERBORGH, J. The big things that run the world - a sequel to E. O. Wilson. Conservation Biology, v. 2, p. 402-403, 1988. 
TERBORGH, J.; WRIGHT, S. J. Effects of mammalian herbivores on plant recruitment in two neotropical forests. Ecology, v. 75, p. 1829-1833, 1994.

TERBORGH, J.; LOPEZ, L.; NUÑEZ, V. P.; RAO, M.; SHAHABUDDIN, G.; ORIHUELA G, RIVEROS M, ASCANIO R, ADLER G, LAMBERT T, BALBAS L. Ecological meltdown in predator-free forest fragments. Science, v. 294, p. 1923-1926, 2001.

TERBORGH, J.; LOPEZ, L.; TELLO, L.; YU, D.; BRUNI, A. R. Transitory states in relaxing ecosystems of land bridge islands. In: LAURANCE, W. F., BIERREGAARD JR., R.O. (Ed.). Tropical forest remnants: ecology, management, and conservation of fragmented communities. Chicago: The Chicago University Press, 1997. p. 124-137

TERBORGH, J.; LOSOS, E.; RILEY, M. P.; RILEY, M. B. Predation by vertebrates and invertebrates on the seeds of 5 canopy tree species of an Amazonian forest. Vegetatio, v. 108, p. 375-386, 1993.

TURNER, I. M. Species loss in fragments of tropical rain forest: a rewiew of the evidence. Journal of Applied Ecology, v. 33, p. 200-209, 1996.

TURNER, I. M.; CHUA, K. S.; ONG, J. S. Y.; SOONG, B. C.; TAN, H. T. W. A century of plant species loss from isolated fragment of lowland tropical rain forest. Conservation Biology, v. 10, p. 1229-1244, 1996.

TURTON, S. M.; FREIDBURGER, H. J. Edge and aspect effects on the microclimate of a small tropical forest remnant on the Atherton Tableland, northeastern Australia. In: LAURANCE, W. F., BIERREGAARD JR., R.O. (Ed.). Tropical forest remnants: ecology, management, and conservation of fragmented communities. Chicago: The Chicago University Press, 1997. p. $45-54$. 
VALLADARES-PÁDUA, C. Black lion tamarin (Leontopithecus chrysopygus): status and conservation. Gainesville, 1987. Thesis (MSc) - University of Florida

VANSCHAIK, C. P.; TERBORGH, J.; WRIGHT, S. J. The phenology of tropical forests: adaptive significance and consequences for primary consumers. Annual Review of Ecology and Systematics, v. 24, p. 353-377, 1993.

VIANA, V. M.; TABANEZ, A. A. J. Biology and conservation of forest fragments in the Brazilian Atlantic moist forest. In: SCHELLAS, J.; GREENBERG, R. (Ed.). Forest patches in tropical landscapes. Washington: Island Press, 1996, p 151-167

VOLTOLINI, J. C.; JESUS, F. Methods for monitoring seed predation and dispersal in a Brazilian Atlantic rainforest. In: INTERNATIONAL SYMPOSIUM ON FRUGIVORY AND SEED DISPERSAL, 3., São Pedro, 2000. Abstracts. Curitiba: Fundação O Boticário de Proteção àNatureza, 2000.

WAHUNGU, G. M.; CATTERALL, C. P.; OLSEN, M. F. Seedling predation and growth at a rainforest-pasture ecotone, and the value of shoots as seedling analogues. Forest Ecology and Management, v. 162, p. 251-260, 2002.

WHITMORE, T. C. Tropical forest disturbance, disappearance, and species loss. In: LAURANCE, W. F., BIERREGAARD JR., R.O. (Ed.). Tropical forest remnants: ecology, management, and conservation of fragmented communities. Chicago: The Chicago University Press, 1997. p . 3-12.

WILIAMSON, G. B.; LAURANCE, W. F.; OLIVEIRA, A. A. DELAMONICA, P.; GASCON, C.; LOVEJOY, T. E. POHL, L. Amazonian tree mortality during the 1997 el Nino dorought. Conservation Biology, v. 14, p. 1538-1542. 2000. 
WILLIAMS, S. E.; MARSH, H. Changes in small mammal assemblage structure across a rain forest open forest ecotone. Journal of Tropical Ecology, v. 14, p. 187-198, 1998.

WILLIAMS-LINERA, G. Vegetation structure and environmental conditions of forest edges in Panama. Journal of Ecology, v. 78, p. 356-373, 1990.

WILLIS, E. O.; ONIKI, Y. (Ed.). Nomes gerais para aves brasileiras. Américo Brasiliense: Gráfica da Região, 1991.

WILLSON, M. F.; WHELAN, C. J. Variation in post dispersal survival of vertebrate-dispersed seeds: effects of density, habitat, location, season, and species. Oikos, v. 57, p. 191-198, 1990.

WILSOM, E. O. (Ed.). Biodiversidade. Rio de Janeiro: Nova Fronteira, 2001. $660 \mathrm{p}$.

WRIGHT, S. J.; DUBER, H. C. Poachers and forest fragmentation alter seed dispersal, seed survival, and seedling recruitment in the palm Attalea butyraceae, with implications for tropical tree diversity. Biotropica, v. 33, p. 583-595, 2001.

WRIGHT, S. J.; ZEBALLOS, H.; DOMÍNGUES, I.; GALLARDO, M. M.; MORENO, M. C.; IBÁÑEZ, R. Poachers alter mammal abundance, seed dispersal, and seed predation in a neotropical forest. Conservation Biology, v. 14, p. 227-239, 2000.

YAHNER, R. H. Changes in wildlife communities near edges. Conservation Biology, v. 2, p. 333-338, 1988.

YOUNG, A.; MITCHELL, N. Microclimate and vegetation edge effects in a fragmented podocarp broadleaf in New Zealand. Biological Conservation, v. 67, p. $63-72,1994$. 
ZAR, J. H. Biostatistical analysis. London: Prentice Hall, 1998.

ZIMMERMANN, C. E. A possível dispersão das sementes de Euterpe edulis (Arecaceae) por aves em abientes degradados. Revista de Estudos Ambientais, v. 1, p. 12-17, 1999.

ZONA, S.; HENDERSON, A. A review of animal-mediated seed dispersal of palms. Selbyana, v. 11, p. 6-21, 1989. 